\title{
The origin of end flare in roll formed profiles
}

\author{
M. Moneke ${ }^{1}$ (D) $\cdot$ P. Groche ${ }^{1}$
}

Received: 26 March 2021 / Accepted: 1 August 2021 / Published online: 27 August 2021

(C) The Author(s) 2021

\begin{abstract}
Roll forming is a continuous manufacturing process designed for large batch sizes. In order to economically produce roll formed parts with smaller batch sizes, the process setup times have to be reduced. During the setup, profile defects and especially the deformation caused by the release of the process-inherent residual stresses, also known as end flare, have to be counteracted. However, the knowledge regarding the creation of residual stresses is limited and the ability to reduce end flare usually depends on the experience of the process designer and the machine operator, which makes the setup time-consuming and cost-intensive. Therefore, in this paper the creation of end flare during the roll forming process is investigated in depth. As a result of this study explanation models for U-, C- and Hat-profiles, which link the creation of residual stresses to the local deformation during the forming process, are developed. Knowing how changes in the forming curve affect the creation of end flare allows to use a knowledge-based approach during the design and setup process, thereby reducing time and costs.
\end{abstract}

Keywords Roll forming $\cdot$ Residual stresses $\cdot$ End flare $\cdot$ Finite element analysis $\cdot$ Explanation model

\section{Introduction}

Due to the global trend of increasing individuality within the product design process and shorter product life cycles, the industrial requirements of forming processes have changed. Nowadays, flexible manufacturing processes are sought that can produce a large number of variants with small batch sizes. In order for the serial production process roll forming to fulfill these requirements, the setup time after a change of the profile geometry has to be minimized. Roll formed products such as seat rails have to be manufactured with a high dimensional accuracy, which requires a high number of forming stations. During the process setup, the forming rolls are manually mounted, a new coil is equipped and the quality of the first parts is investigated. Due to imperfect roll design and roll positions, wear and tear or fluctuations in the material properties, deviations from the dimensional accuracy and profile defects can occur, which have to be manually corrected before the

M. Moneke

moneke@ptu.tu-darmstadt.de

1 Technische Universität Darmstadt, Institute for Production Engineering and Forming Machines, 64287 Darmstadt, Germany serial production starts. The effectiveness of the correction measures depends on the experience of the roll designer and the machine operator. The setup process affects the production efficiency, as it significantly decreases the amount of the machine time that can be used to produce parts.

Especially the profile deformation at the cut-off, which is known as end flare and occurs due to process-inherent residual stresses (Fig. 1), has to be precisely counteracted to satisfy production tolerances [1]. Since the creation of residual stresses during roll forming depends on the actual forming conditions at the roll forming machine, whereas the deformation can only be observed after the cutting, the correction process is time-consuming and creates waste.

Therefore, the objective of this study is to reach a deeper process understanding regarding the creation of end flare of U-, C- and Hat-profiles. While the responsible stresses and the corresponding types of profile deformations are known, the relation between the forming curve, plastic yielding and the creation of residual stresses has not been investigated yet. In this study, the forming process is divided into forming steps depending on the longitudinal curvature and the corresponding longitudinal, transversal and shear stresses are analysed with regard to plastic yielding and the creation of residual stresses. After a parameter study, the results are converted into explanatory models. 
Fig. 1 Profile deformation after cutting roll formed profiles

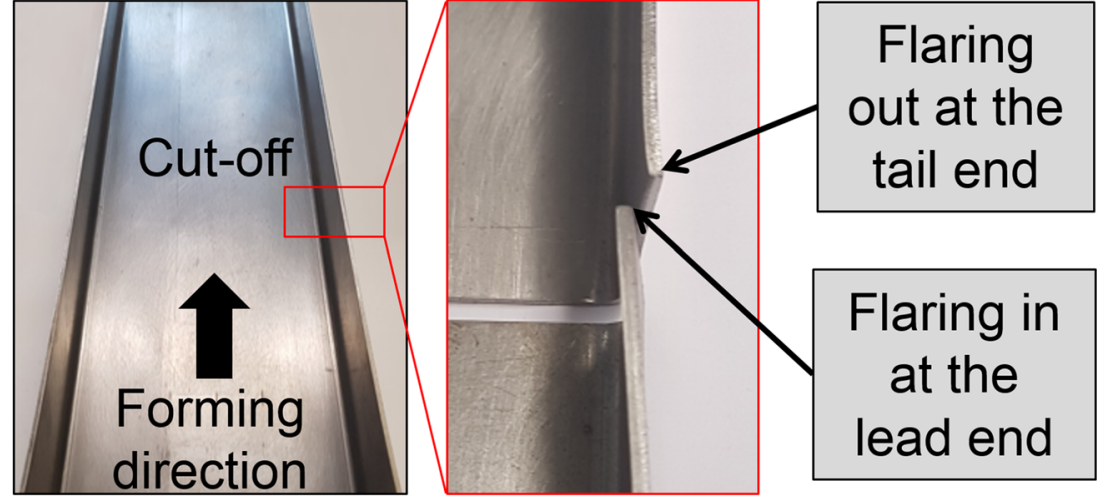

\section{State of the art}

\section{Roll forming}

Roll forming is a continuous production process in which sheet metal is gradually transformed into the desired crosssectional geometry as it is bent in transversal direction while passing through consecutive forming stations in longitudinal direction [2]. Forming takes place at room temperature without any intended reduction of the sheet thickness [3]. The possibility to produce parts of any length in combination with a wide spectrum of possible profile geometries makes roll forming an important production process within the automotive, construction or furniture industry. With a forming speed up to $200 \mathrm{~m} / \mathrm{min}$ [4] and the possibility of integrating additional operations like cutting or welding at any point of the forming line, roll forming allows for an economically efficient serial production compared to other beding processes [5].

Characteristic for roll forming is the creation of a 3dimensional forming zone when the sheet is bent in transversal direction while it moves in longitudinal direction [6].

At the beginning of the forming process, the sheet is lifted upwards in longitudinal direction by the lower rolls, before it is guided into the roll gap through contact with the upper roll. Thereby, the flange is bent in transversal direction and bent back in longitudinal direction so that the band edge and the undeformed profile web move again parallel to each other. There is a line contact between the flange and the lower roll, which is initiated at the band edge and extends towards the bending zone (see also Fig. 2). The flange moves along a concave convex forming curve, whereby the direction of the curvature changes from concave to convex along the contact line with the lower roll [7]. The forming curve of the band edge is longer than the path of movement of the non-deformed profile web because of the transversal and longitudinal bending load. Thus, the flange is subjected to homogenous longitudinal strains (constant over the sheet thickness) in addition to the bending strains [2]. Due to the transversal and longitudinal bending load, shear strains are induced so that overall transversal, longitudinal and shear strains occur both as bending strains and as homogenous strains [8].

The part of the forming curve between the beginning of deformation and the roll axis is known as deformation length, which is analytically approximated as a straight line by Bhattacharyya et al. and is affected by the bending angle, flange length and material thickness [9].

Panton et al. describe the bending angle curve during forming, taking into account the curvature of the forming curve and geometric boundary conditions, which model the initial contact with the lower roll. The concave convex contour of the bending angle curve is described separately for both parts and it is assumed that the convex part coincides with the contour of the lower roll. [7]

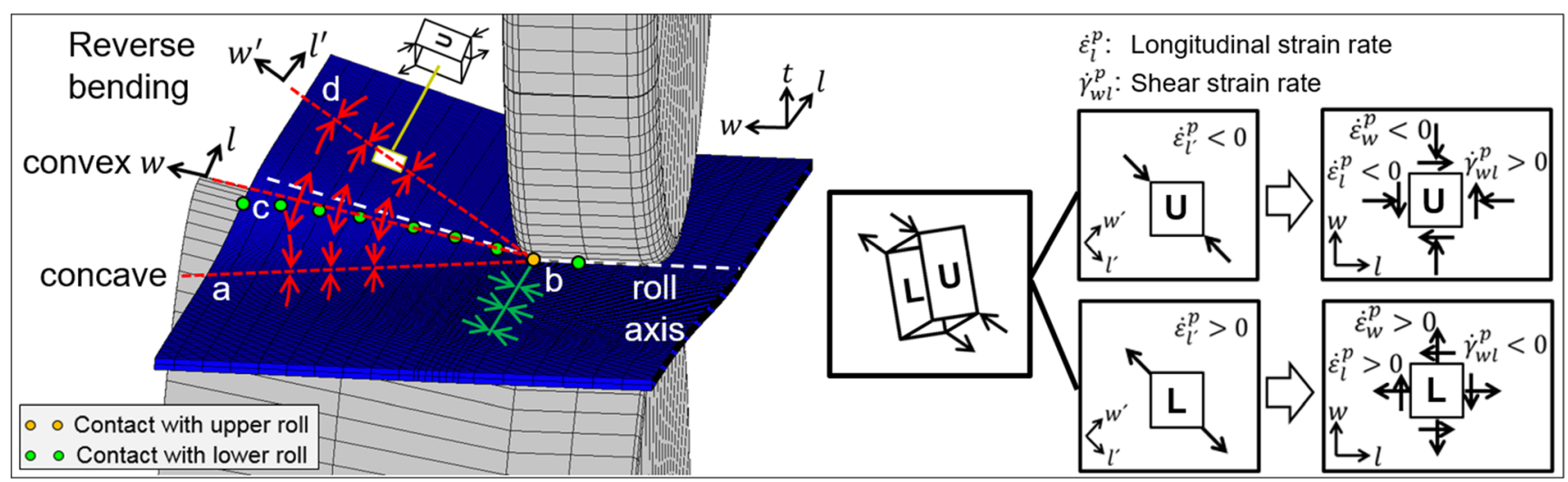

Fig. 2 Contact, bending loads and plastic deformation during roll forming of a U-profile (U: Upper side, L: Lower side, based on [22]) 
Liu et al. adapt the model in case formgiving side rolls are used instead of formgiving lower rolls [10]. Abeyrathna et al. can show that the convex curvature of the bending angle curve does not coincide with the contour of the lower roll and that the flange takes on a larger curvature radius [11].

Except for the desired transversal plastic bending, other plastic deformation is unwanted. If significant plastic longitudinal strain is induced into the flange, profile defects like longitudinal curvature, canning or edge waves can occur [2]. The maximum longitudinal strain depends, among other things, on the flange length [12], the sheet thickness [13], the yield strength [14], the roll diameter [15], the station distance [16], the calibration method [17] and the bending angle [18]. An uneven distribution of the longitudinal strain across the cross section can also lead to horizontal and vertical curvatures [19], waves in the profile web [20] or a twisting of the profile [19].

Dimensional deviations from the profile geometry arise further as a result of springback as well as due to the release of process-inherent residual stresses when the profile is cut to length. The release of the residual stresses leads to a deformation of the profile ends at the cut-off, which is also referred to as end flare [2].

\section{Residual stresses in roll forming}

Already in early experimental studies on roll forming, based on the occurring profile deformation when cutting a U-profile, the effect of a torsional and longitudinal bending moment was discovered [21]. Since the sheet metal experiences springback in transversal direction, no significant residual transversal stresses remain in the flange [22]. The responsible shear and longitudinal residual stresses arise as a result of the threedimensional forming of the flange and are inhomogenously distributed over the sheet thickness [21]. The residual stresses, which remain within the bending zone, do not contribute to end flare, as they do not lead to a profile deformation when the profile is cut to length $[21,22]$. The forming curve of the flange when roll forming a U-profile as well as the contact zones and bending loads (upper side) are displayed in Fig. 2.

The generation of the residual stresses is described by Saffe et al. as follows: The flange is concavely bent around the axis b$\mathrm{a}$ in longitudinal direction before it is convexly bent around the lower roll (axis b-c). During the convex bending, significant plastic shear and longitudinal strains occur in the A-B-C area. The flange is reversely bent and sheared back around the axis b-d so that flange and profile web move again parallel to each other. [22]

During the reverse bending (point $\mathrm{D}$, axis b-d), the material experiences a bending and torsional moment. On the upper side of the flange $(\mathrm{U})$, compressive residual stresses in longitudinal direction and positive residual shear stresses (in the plane of the sheet) remain, while on the lower side (L) tensile residual stresses in longitudinal direction and negative residual shear stresses remain.
When a profile is cut to length, the residual stresses are released, whereby the residual longitudinal stresses cause a bending moment and the residual shear stresses cause a torsional moment. The associated profile deformations are shown in Fig. 3. [22]

The torsional moment causes a flaring in at the lead end and a flaring out at the tail end, while the bending moment causes a flaring out at both profile ends. The profile deformation results from the superposition of both deformations, whereby the bending moment reduces the flaring in caused by the torsional moment at the lead end and increases the flaring out at the tail end. Due to the superposition of opposite deformations at the lead end, a turning point is formed, whereby the flange end flares in as a whole, but the tip of the flange is turned outwards. The typical end flare of a U-profile is characterized by a flaring in at the lead end and a flaring out at the tail end, whereby the tail end flares out stronger than the lead end flares in. [23]

Due to the strong dependency of end flare on the local contact state between flange and rolls as well as the associated plastic shear and bending strains, the profile deformation varies depending on the actual forming conditions. As a result, end flare can differ for every profile geometry and the deformation can change after each forming step. [24, 28]

\section{Hat-profile}

The characteristic end flare of Hat-profiles is a flaring out of the longer, inner flanges at both profile ends [23, 25, 26], while the shorter, outer flanges flare in at the lead end and flare out at the tail end [27]. Due to the opposite bending direction of the inner and outer flanges during the forming process, the release of residual stresses creates torsional moments as well as bending moments that oppose each other [27].

The influence of the outer flanges is experimentally investigated by Ona and Jimma, who can show that when the outer flanges of a Hat- or C-profile are removed (longitudinal cut) and the remaining U-profile is cut to length (transversal cut), end flare at the inner flanges occurs in the form of a flaring in at the lead and a flaring out at the tail end. In contrast, when the entire profile is cut to length, the longer, inner flanges flare out at both sides. Further investigations show that if the length of the shorter, outer flanges is below $8 \mathrm{~mm}$, the longer, inner flanges also flare in at the lead end and flare out at the tail end. In addition, the greater the length of the outer flanges, the smaller the end flare at the inner flanges. [23]

Moneke and Groche can further show that the forming strategy of the inner and outer flanges (simultaneous vs. sequential bending) greatly affects end flare. During the sequential forming of a Hat-profile, the flange, which was bent last, experiences significant end flare, while the flange, which was bent previously in the opposite direction, experiences strongly reduced end flare. Through the bending angle sequence, the distribution of the residual stresses along the cross section can 

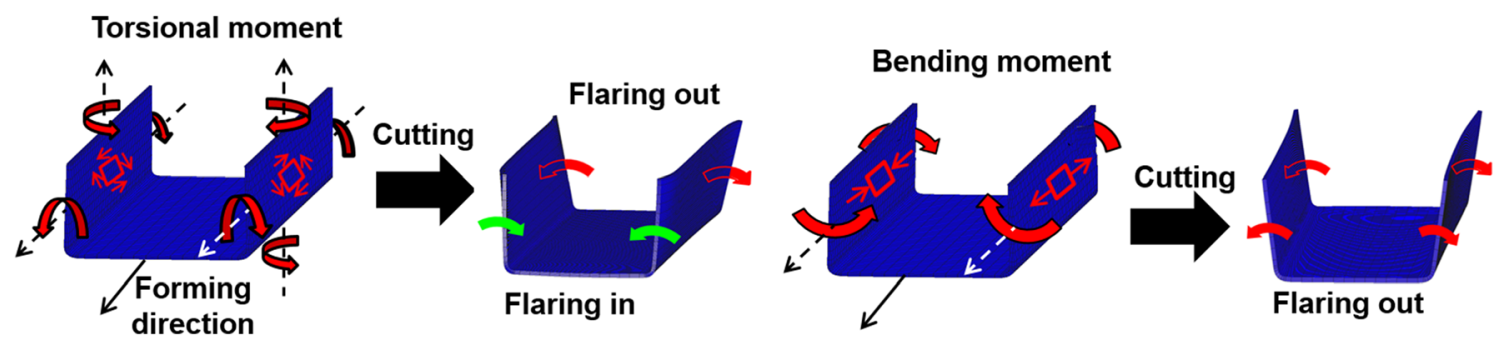

Fig. 3 Moments and profile deformations due to the release of residual stresses (based on [22])

be affected, which allows to control in which parts of the profile significant residual stresses remain. [28]

\section{C-profile}

Ona and Jimma experimentally investigate the end flare of a C-profile and find analogous to the investigation regarding the Hat-profile that if the outer flanges are short, the inner flanges flare in at the lead end and flare out at the tail end. With increasing length of the outer flanges, the end flare of the inner flanges changes to a flaring out at both profile ends. In contrast to the investigation on Hat-profiles, end flare at the longer, inner flanges increases when the length of the shorter, outer flange increases [23].

\section{Tubular profiles}

End flare when roll forming rectangular tubes from a round tube was described by Nagamachi et al. [29]. It is shown that end flare is characterized by a flaring out in width and height direction, whereby the deformation at the tail end is stronger than the deformation at the lead end [29]. The longitudinal strains induced as a result of the reduction of the cross section cause strong residual longitudinal stresses so that the bending moment has a higher impact on end flare than the torsional moment [29].

\section{Counter measures}

To avoid end flare, usually two types of counter measures are applied. One the one hand, counter measures that induce opposite directed plastic strains during the forming process to counterbalance the distribution of residual stresses along the cross section. This is done by overbending and bending back [23] or by lowering and elevating the profile [27]. Regarding end flare of U-profiles, Moneke and Groche showed that by reducing the roll gap (no sheet thickness reduction due to the stiffness of the forming station), the bending load during the convex bending and reverse convex bending of the forming curve (Fig. 2) can be increased [30]. This allows to counterbalance the residual shear stresses at the cost of partially increased residual longitudinal stresses. In contrast to overbending and bending back, end flare can not be completely removed and a slight flaring out at both profile ends remains.
On the other hand, counter measures that use an additional plastic deformation to change the distribution of residual stresses. Ona et al. induced plastic strains by using a punch to compress the flanges of thick-walled U-profiles while a die prevented the flanges from buckling. [31]

\section{Experimental setup and numerical model}

\section{Experimental setup}

The experimental investigation is conducted with a U-profile made of CR300LA $\left(R_{p 0,2}=318 \mathrm{MPa}\right)$ that has the dimensions as shown in Fig. 4.

The roll forming line consists of 6 forming stations ( $\mathrm{S} 1$ S6) with bending angles of $13^{\circ}, 29^{\circ}, 47^{\circ}, 65^{\circ}, 80^{\circ}$ and $90^{\circ}$ and a distance of $540 \mathrm{~mm}$ between stations. While in the first three stations the sheet is formed by upper and lower rolls, in stations 4 to 6 formgiving siderolls are applied. Station 6 is the only station, where the flange has contact with the rolls on both sides during the forming. The diameter of the lower rolls is $250 \mathrm{~mm}$, while the diameter of the upper rolls is $250 \mathrm{~mm}$ in the first three stations and $300 \mathrm{~mm}$ in the following stations. The bending radius of $3 \mathrm{~mm}$ remains constant, but the arc length increases in every forming step, whereby the material that forms the bending zone is taken out of the flange. Sheets with a length of $1400 \mathrm{~mm}$ and an initial width of $175 \mathrm{~mm}$ are
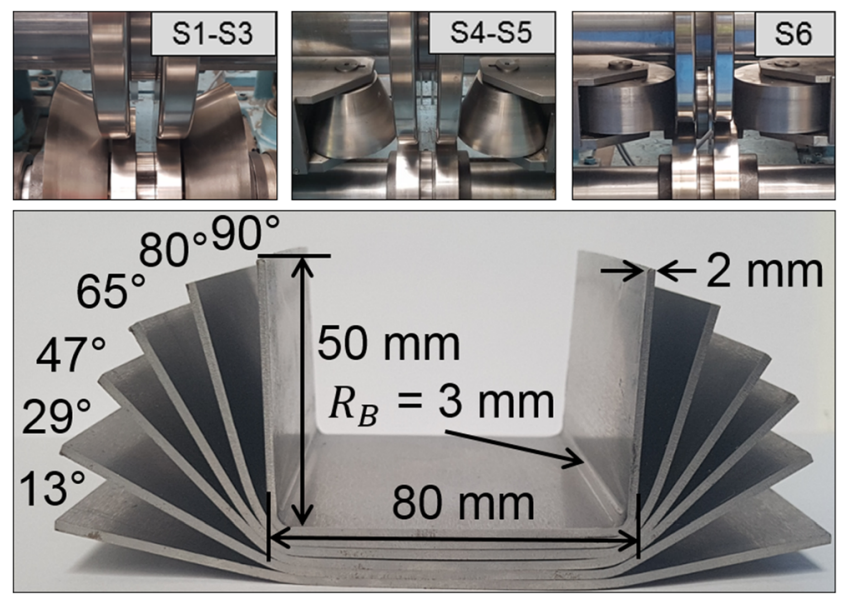

Fig. 4 Bending angle sequence and geometry of the investigated Uprofile 
used. No lubrication is applied and the speed of the forming line is set to $1 \mathrm{~m} / \mathrm{min}$. After roll forming, sections of $100 \mathrm{~mm}$ are cut off at the profile ends because these ends are subjected to additional deformation when the sheet moves in and out of the forming stations.

The remaining profile is cut into 3 parts with a length of $400 \mathrm{~mm}$ each and the bending angle is measured in the middle and at the profile ends of each part with the optical 3D scanner GOM ATOS [32]. End flare is calculated as the difference between the bending angle measured in the middle and the bending angle measured at the profile ends. It is measured at the right and left side of all three parts so that for the lead end and tail end each 6 measurements are obtained. For every parameter investigated in this study 2 sheets are used so that end flare is calculated as the average of 12 measurements (see also Fig. 6).

\section{Numerical model}

For the numerical study the commercially available finite element software package Marc Mentat 2012 is used, whereby an implicit quasi static solver is applied. The numerical model is shown in Fig. 5.

The numerical model is designed with the objective to predict end flare, whereby process characteristics that do not significantly affect end flare are neglected [1]. Therefore, several simplifications are made in the numerical study, compared to the experimental investigations. Due to the symmetry of the profile geometry, only half of the profile is simulated. The sheet length is reduced to $1200 \mathrm{~mm}$ in order to save computational time. Friction is not considered, as previous studies have shown no significant improvement of the model accuracy (bending angle [33], shift of the unlengthened layer [34]), when friction is considered [33, 34]. Instead, the sheet (deformable body) is moved by a displacement boundary condition, which is placed at the front end of the sheet web, through the fixated forming stations (rigid bodies). In accordance with the assumption of a quasi static process the sheet velocity is set to $0.25 \mathrm{~mm} / \mathrm{s}$.

An isotropic elastic plastic material model is applied, whereby flow curves are experimentally obtained by tensile tests and extrapolated using the Ludwik equation. This material model has shown in previous studies to be sufficient to accurately model end flare for complex profile geometries [24, 28]. For discretization elements of type 7 (Three-dimensional, eight-node, arbitrary hexahedral, first-order, isoparametric element [35]) are used. In order to avoid volumetric and shear locking in bending processes [36], the assumed strain formulation and constant dilatation formulation are used [37]. Based on a convergence analysis and previous studies [28], two elements over the thickness are used. Similar results are obtained by Nagamachi et al., who compared three and six elements in thickness direction and found no significant differences regarding the distribution of residual shear and residual longitudinal stresses [29].

It has to be noted, that the requirements regarding the simulation of end flare significantly differ from the requirements regarding the simulation of springback. Modelling springback requires a detailed modelling of the plastic deformation within the bending zone, due to the transversal bending, while modelling end flare in contrast requires an accurate modelling of the plastic deformation within the flange, due to longitudinal bending and shear deformation. Simulation models designed to accurately model springback require around 25

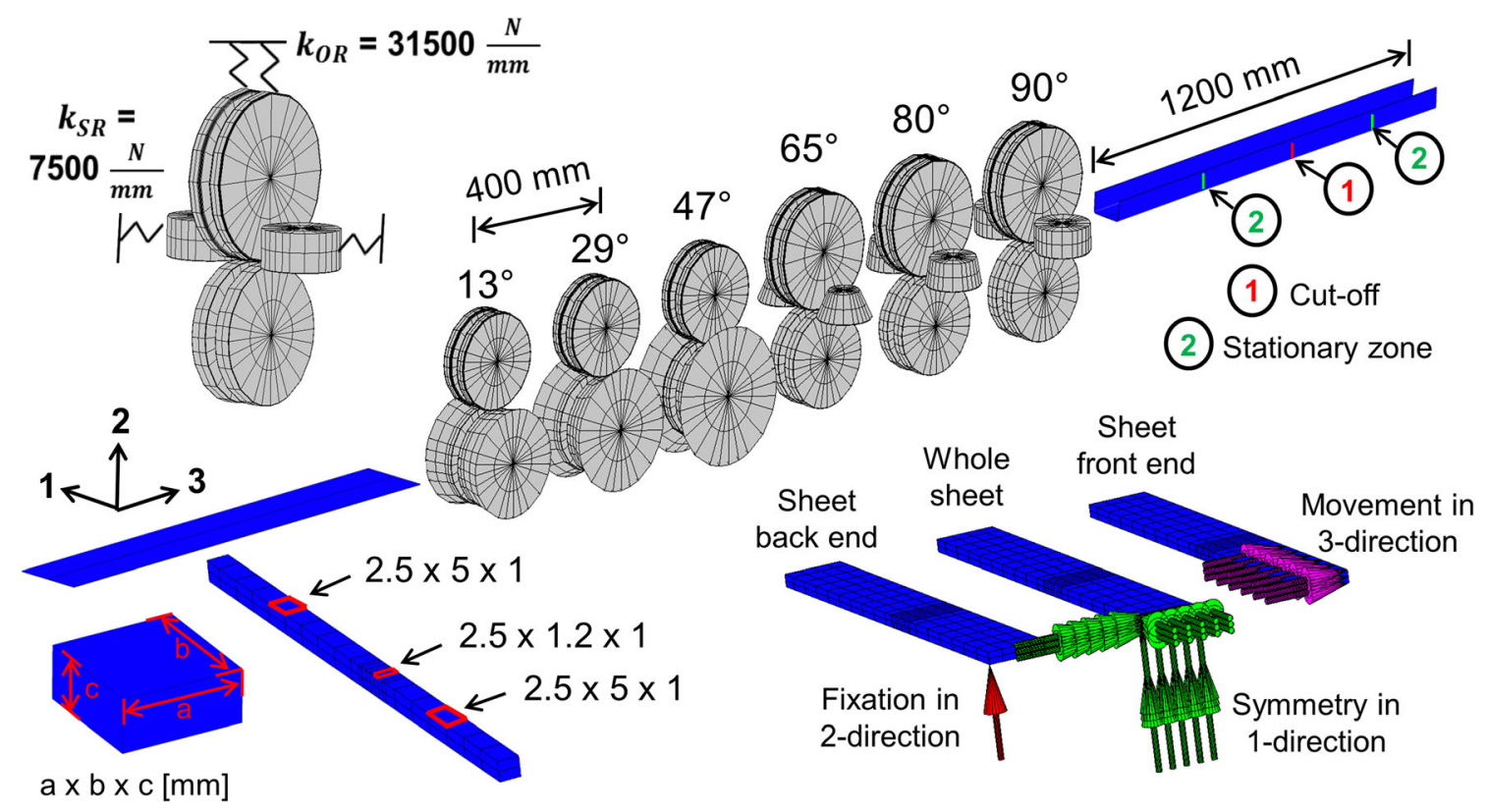

Fig. 5 Numerical model of the roll forming process 
through-thickness integration points within the transversal bending zone [38, 39]. Furthermore, material models that capture the variation of the elastic modulus depending on the amount of plastic strain can improve the prediction accuracy of springback [39, 40]. Abvabi et al. (2017) showed that by using the Yoshida-Uemori material model, which accounts for the variation of the elastic modulus during plastic deformation under cyclic loading and unloading, the numerical prediction of springback of roll formed profiles can be improved [39]. Since the plastic deformation within the flange is significantly lower than the plastic deformation within the bending zone (Fig. 12), the variation of the elastic modulus has a significantly lower effect on the simulation of end flare. Therefore, a material model with isotropic hardening as well as 2 elements over the thickness are chosen for the prediction of end flare.

To cut the profile after the roll forming, a row of elements in the middle of the sheet is deleted so that the residual stresses are released and the profile ends at the cut-off are deformed as shown in Fig. 6.

\section{Discussion of results}

\section{Analysis of the creation of residual stresses during the forming of a U-profile}

The distribution of plastic strains and stresses during the forming in the first station $\left(13^{\circ}\right)$ is shown in Fig. 7.

Zones of significant plastic deformation $\left(P_{U, 1}-P_{U, 8}\right)$, the contact point between sheet metal and lower roll $\left(C_{L R}\right)$ as well as characteristic points or sections $(\mathrm{I}-\mathrm{V})$ are shown. At the beginning of the forming process, the sheet metal is lifted upwards by the lower roll, before it is pushed downwards by the upper roll and guided into the roll gap. Thereby, the flange is bent in transversal direction while it is simultaneously bent around the contour of the lower roll in longitudinal direction. After passing the roll gap, the flange is bent back so that band edge and profile web move again parallel to each other. During the forming process, the flange moves along a concave convex curve (path I), whereas the area around the bending zone is subjected to a slight longitudinal bending around the contour of the upper roll (path V). The simultaneous transversal and longitudinal plastic bending within the bending zone $\left(P_{U, 4}\right.$ and $\left.P_{U, 7}\right)$ induces opposite directed shear strains $\left(P_{U, 1}\right.$ and $P_{U, 2}$ ) in the sheet web and the flange (in plane, 1-3-direction). Due to the stronger bending deformation of the flange, the plastic shear strains in the flange are significantly higher $\left(P_{U, 2}\right)$. While near the bending zone (Path IV) the flange is mainly subjected to transversal bending, towards the band edge the transversal bending load decreases and the longitudinal bending load as well as the longitudinal homogenous strains increase. Therefore, the highest longitudinal plastic strains occur at the band edge $\left(P_{U, 6}\right)$. Since the longitudinal strains are balanced along the cross section, compressive longitudinal strains are induced in the lower part of the flange $\left(P_{U, 5}\right)$. Plastic transversal strains at the band edge $\left(P_{U, 8}\right)$ are not induced due to transversal bending, but rather due to transversal contraction resulting from the longitudinal strain. Resulting from the switch of the bending deformation from transversal to longitudinal bending deformation, plastic shear strains decrease in the middle of the flange (Path II) and increase again near the band edge $\left(P_{U, 3}\right.$ near path I). Figure 8 shows plastic strains and stresses along the band edge (path I) during the forming in the first station.

Stresses are displayed at the upper (drawn through line) and the lower side (dotted line) of the profile. The longitudinal stresses at the upper side are further divided into the longitudinal homogenous stresses $\sigma_{33, \text { Hom. }}=\left(\sigma_{33, \text { upper }}+\sigma_{33, \text { lower }}\right) / 2$ and the longitudinal bending stresses $\sigma_{33}$, Bend. $=\left(\sigma_{33}\right.$, upper $\sigma_{33}$, lower $) / 2$. The forming process consists mainly of three forming steps, namely concave bending (2a), convex bending (3a) and reverse convex bending (4a), whereby the longitudinal bending stress changes its direction around $2 \mathrm{~b}$ and $3 \mathrm{~b}$ before a steady state is reached after the forming (4b). Since plastic yielding is discontinuous, the beginning of plastic deformation within each forming step is indicated (e.g. $P_{2}^{L}$ ), whereby it is distinguished between the lower (L) and the upper side (U) of the profile.

During the concave bending (2a), the induced tensile longitudinal homogenous stresses are stronger than the
Fig. 6 Measurement of end flare after roll forming (Whole profile is shown for better visibility)
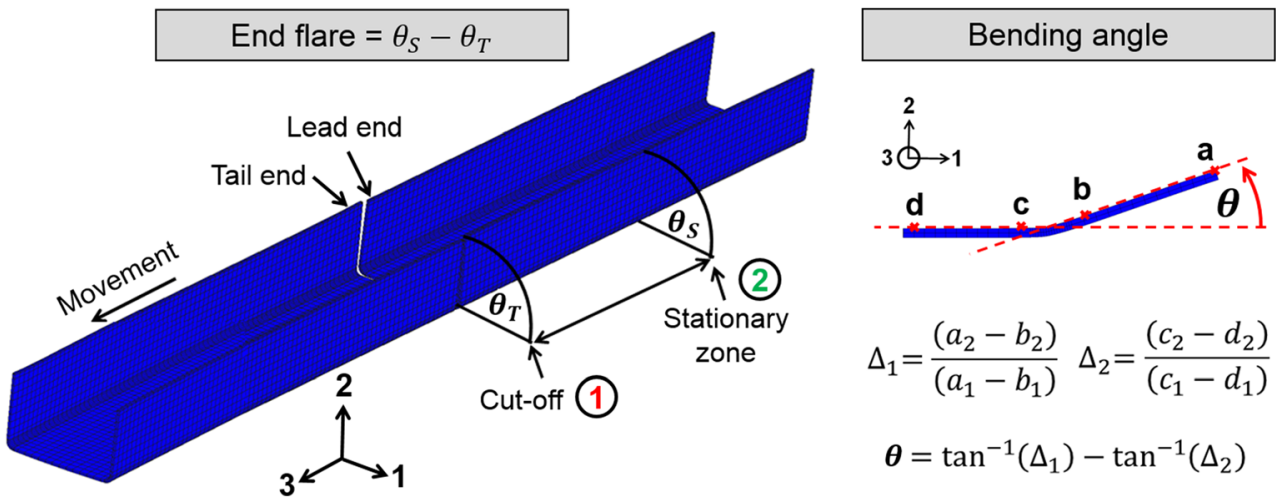

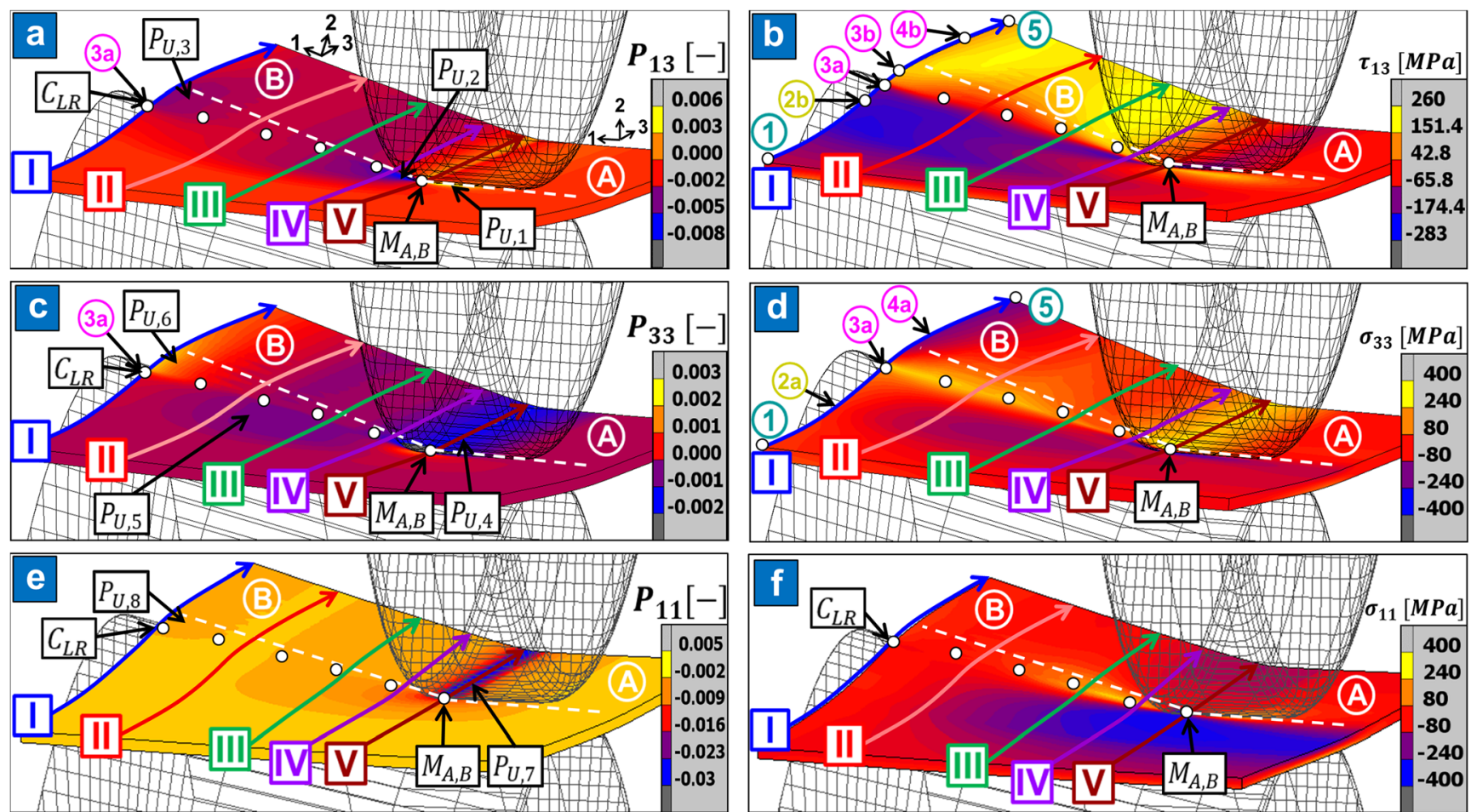

Fig. 7 Plastic shear (a), longitudinal (c) and transversal (e) strains as well as shear (b), longitudinal (d) and transversal (f) stresses during the forming of a U-profile in the first station

longitudinal bending stresses so that tensile longitudinal stresses occur at the upper and lower side of the flange. As a consequence of the shifted longitudinal stresses, plastic yielding first occurs at the lower side $\left(P_{2}^{L}\right)$, whereby not an individual stress exceeds the yield limit $\left(k_{f}=R_{p 0,2}=318 \mathrm{MPa}\right)$, but the von Mises stress does. Plastic longitudinal strains and plastic shear strains occur at the same time. The longitudinal bending stress first reaches a local maximum corresponding to the concave curvature of the flange, before the bending stress is reversed as the curvature transitions from concave to convex. After the change of direction (2b), the longitudinal bending stress reaches its maximum value due to the convex bending (3a) at the contact point with the lower $\operatorname{roll}\left(C_{L R}\right)$. As a result of the directional change of the longitudinal bending stress ( $2 b)$, a change of direction of the shear stress is induced as well. Therefore, the shear stress decreases (starts around $2 \mathrm{~b}$ ), changes direction (3a) at the contact point with the lower roll $\left(C_{L R}\right)$ and increases again. The plastic deformation on the lower side of the flange stops after the longitudinal bending stress has decreased during the directional change (2b), before the increase due to the convex bending (3a) leads to renewed plastic flow $\left(P_{3}^{L}\right)$. Following the directional change of the longitudinal bending stress, the plastic longitudinal bending strain changes direction (3a) at the contact point $\left(C_{L R}\right)$ and then reaches its maximum value ( $3 b)$. In this case, the strains reach a plateau, which is shifted in positive direction due to the homogenous longitudinal strain. The maximum plastic shear strain is reached at the contact point with the lower roll $\left(C_{L R}\right)$, where the directional change of the plastic longitudinal homogenous strain also takes place (3a). The reverse convex bending, which reduces the convex curvature so that flange and web move parallel again,
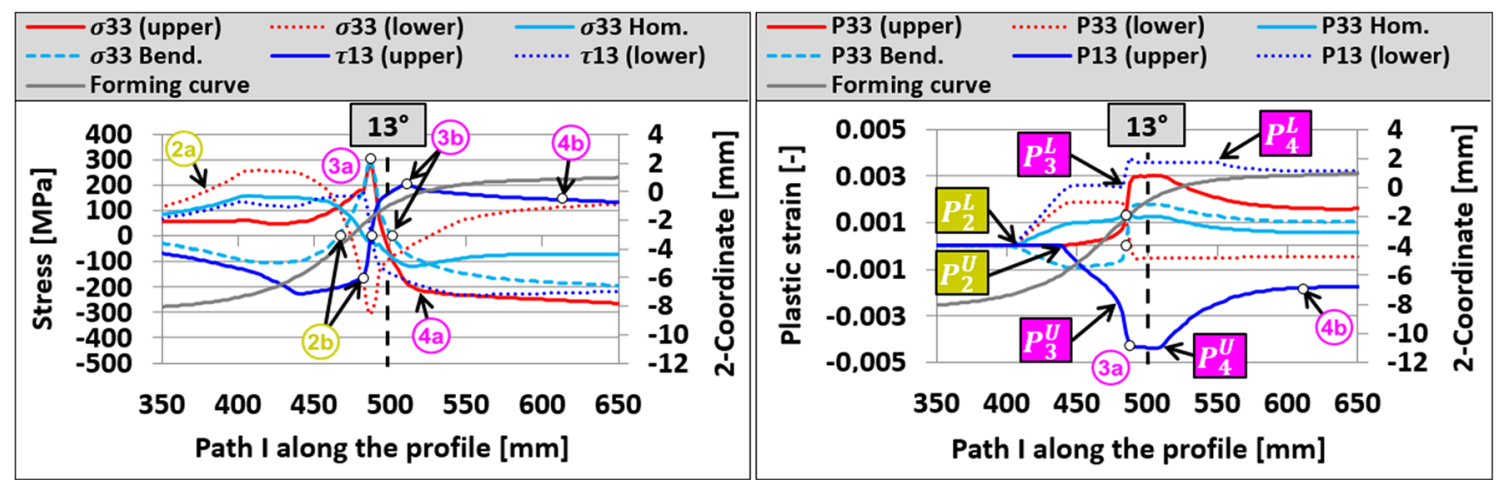

Fig. 8 Plastic shear strains and stresses as well as plastic longitudinal strains and stresses along path I 
induces a longitudinal bending stress which acts against the previously generated plastic strains. Therefore, the longitudinal bending stress changes direction again (3b) after reaching its maximum (3a). Additionally, the homogenous longitudinal stress changes direction at the contact point with the lower roll (3a), which increases the longitudinal stress on the upper side and reduces it on the lower side. For this reason, plastic flow first occurs a the upper side of the sheet $\left(P_{4}^{U}\right)$ and then on the lower side $\left(P_{4}^{L}\right)$ when the flange is bent back (4a). The directional change of the longitudinal bending stress ( $3 \mathrm{~b}$ ) also leads to a change in the shear stress, whereby the shear stress reaches a maximum (3b) and decreases again (4a) until the end of the forming process $(4 \mathrm{~b})$.

During the reverse convex bending (4a), the plastic homogenous strain induced by the concave bending and the plastic longitudinal bending strain resulting from the convex bending are partially reduced (up to $4 \mathrm{~b}$ ), whereby the decrease at the upper side is significantly greater due to the strengthening effect of the homogenous longitudinal stress. Within the profile residual stresses remain that act against the plastic longitudinal bending strains due to the convex bending and are shifted depending on the homogenous residual longitudinal stresses (4b). The convex bending (from $3 a$ onwards) also leads to a partial reduction of the plastic shear strain (4a) that is previously generated during the concave bending. Therefore, residual shear stresses remain in the flange, which act against the plastic shear strain due to the initial concave bending ( $4 b$ ). Due to the influence of the homogenous part of the longitudinal stress on the beginning of plastic yielding on the upper and lower side, the plastic shear strain is also shifted in the direction of positive strains. As a result, even though the shear stress does not have a significant homogenous part, residual shear stresses with a homogenous part remain.

\section{Plastic strain and stresses during forming in stations 1 and 2}

After looking at the forming mechanism in detail, the influence of the residual stresses on plastic deformation in subsequent forming stations is investigated. The shear, longitudinal and transversal plastic strains and stresses during the forming in station $1\left(13^{\circ}\right)$ and $2\left(29^{\circ}\right)$ are shown in Fig. 9.

As explained above, it can be seen that plastic deformation is caused due to the von Mises stress exceeding the yield limit. During the forming in station 2, the creation of plastic strains is significantly influenced by the residual stresses remaining after station 1 . Since the residual shear stresses act in opposite direction to the shear stresses induced by the concave bending, the shear stresses are significantly lower than during the concave bending in station 1 . On the contrary, the residual longitudinal stresses act in the same direction as the longitudinal bending stresses. The amplification of the longitudinal stresses is sufficient to enable plastic yielding $\left(P_{2}^{L}\right)$, although, due to the low shear and transversal stresses, only the plastic longitudinal strain changes slightly. During the convex bending $\left(P_{3}^{L, U}\right)$ and reverse convex bending $\left(P_{4}^{L, U}\right)$, no significant plastic deformation occurs. Therefore, the residual shear stresses take on values comparable to those after station 1. As a result of the plastic deformation $\left(P_{2}^{L}\right)$, the residual longitudinal stresses on the lower side are shifted into the compressive area so that the longitudinal stresses induced on the lower side during the concave bending in station 3 are further reduced. This shows that the effect of the residual longitudinal stresses on the creation of plastic strains in the following stations greatly depends on the homogenous longitudinal stresses. Plastic strain and stresses along path II (Fig. 7) are shown in Fig. 10.

Without the impact of longitudinal homogenous stresses, plastic yielding starts simultaneously at the upper and lower side of the flange $\left(P_{2}^{L, U}\right)$ during the forming in station 1. Corresponding to the lower longitudinal bending and shear loads, lower plastic strains occur. The plastic longitudinal bending strains induced during the concave $\left(P_{2}^{L, U}\right)$ and convex $\left(P_{3}^{L, U}\right)$ bending compensate one another. Therefore, during the reverse convex bending, no opposite directed longitudinal bending stress is induced, but the stress is reduced similar to an elastic deformation and low residual longitudinal stresses remain. Corresponding to the longitudinal bending stress, the stress gradient of the shear stress after the

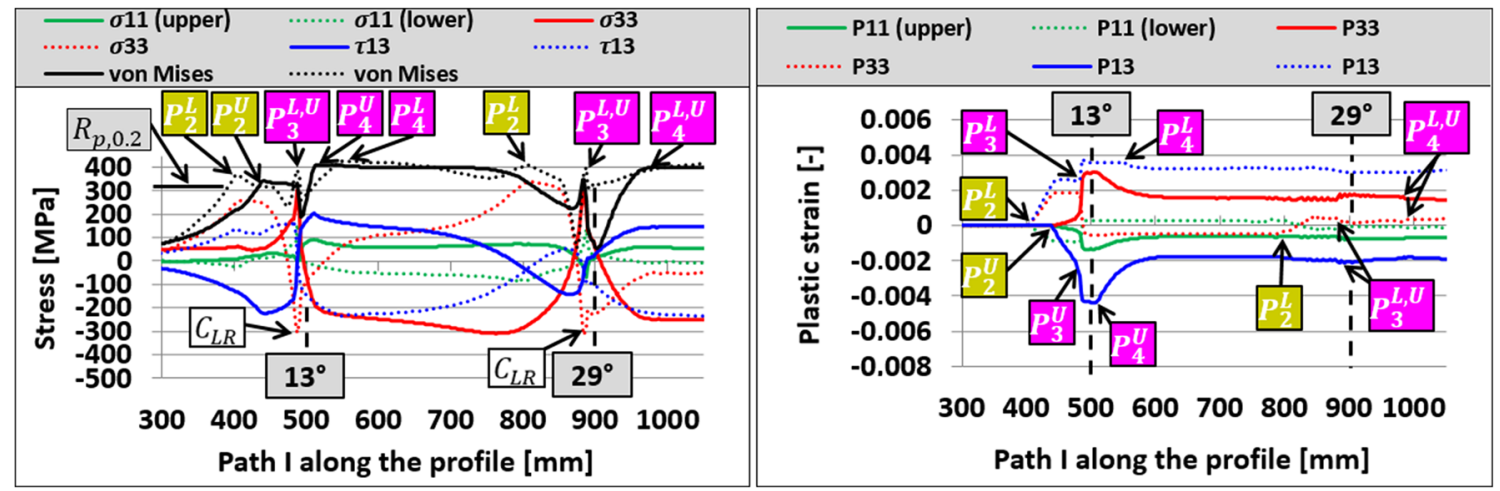

Fig. 9 Plastic strain and stresses along path I during the forming in station 1 and 2 

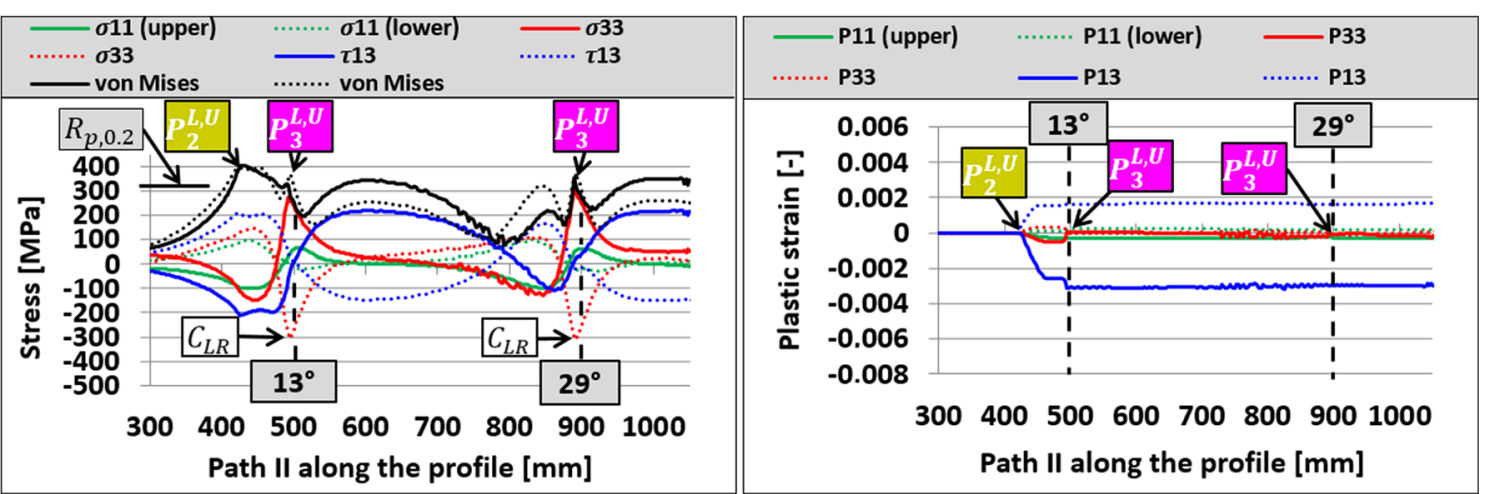

Fig. 10 Plastic strain and stresses along path II during the forming in station 1 and 2

directional change $\left(C_{L R}\right)$ is small so that the shear stress induced during the convex bending is not sufficient to enable plastic yielding. Therefore, there is no reduction of the plastic shear strain generated during the the concave bending and significant residual shear stresses remain.

Regarding the forming in station 2, the residual shear stresses reduce the shear stresses that are induced during the concave bending so that no plastic deformation occurs. Only at the point of contact with the lower roll $\left(C_{L R}\right)$, where the longitudinal bending stress reaches its maximum, the longitudinal stress briefly exceeds the yield limit. This means that, although the bending angle difference from station 1 to station $2\left(16^{\circ}\right)$ is greater than the bending angle in the first station $\left(13^{\circ}\right)$, the residual stresses prevent significant plastic deformation in the flange. Plastic strain and stresses along path IV are shown in Fig. 11.

During the forming in station 1, the deformation in the lower part of the flange (path IV) is mainly caused by the forming of the bending zone. Therefore, only low longitudinal bending stresses and plastic strains occur in the lower part of flange B. Instead, plastic yielding mainly occurs due to concave convex transversal bending $\left(P_{2}^{L, U}\right)$. The course of the transversal bending stress is similar to the longitudinal bending stress in the upper part of the flange, as the transversal stress reaches its maximum during the convex bending at the contact point with the lower roll $\left(C_{L R}\right)$. Low plastic strains and residual stresses remain after the reverse convex bending and the occurrence of springback $\left(P_{3+4}^{L, U}\right)$. Due to the shearing of the material during the forming of the bending zone $\left(P_{U, 1}\right.$ and $\left.P_{U, 2}\right)$ in combination with the simultaneous longitudinal and transversal bending, the plastic shear strain is the highest in the lower part of the flange. During the convex bending and the reverse convex bending, the shear strain, which is induced by the concave bending, is only partially reduced so that significant residual shear stresses remain. The shear, transversal and longitudinal residual stresses have no significant influence on plastic yielding during the forming in station 2 , since the transversal bending stress alone is sufficient to cause plastic yielding.

\section{Distribution of residual stresses along the cross section}

The residual plastic strains and residual stresses along the cross section after station 1 are displayed in Fig. 12.

The highest plastic strain $(\sim 0.085)$ is induced within the bending zone because of transversal bending (P11). Due to springback, only small transversal residual stresses remain in the lower area of the flange, which do not cause any significant deformation of the flange when it is cut to length. The distribution of the shear and longitudinal stresses that cause end flare can be divided into characteristic sections $(5 \mathrm{a}-5 \mathrm{~g})$. The bending zone $\mathrm{A}$ is characterized by high residual longitudinal stresses $(5 \mathrm{c})$ and the directional change of the residual

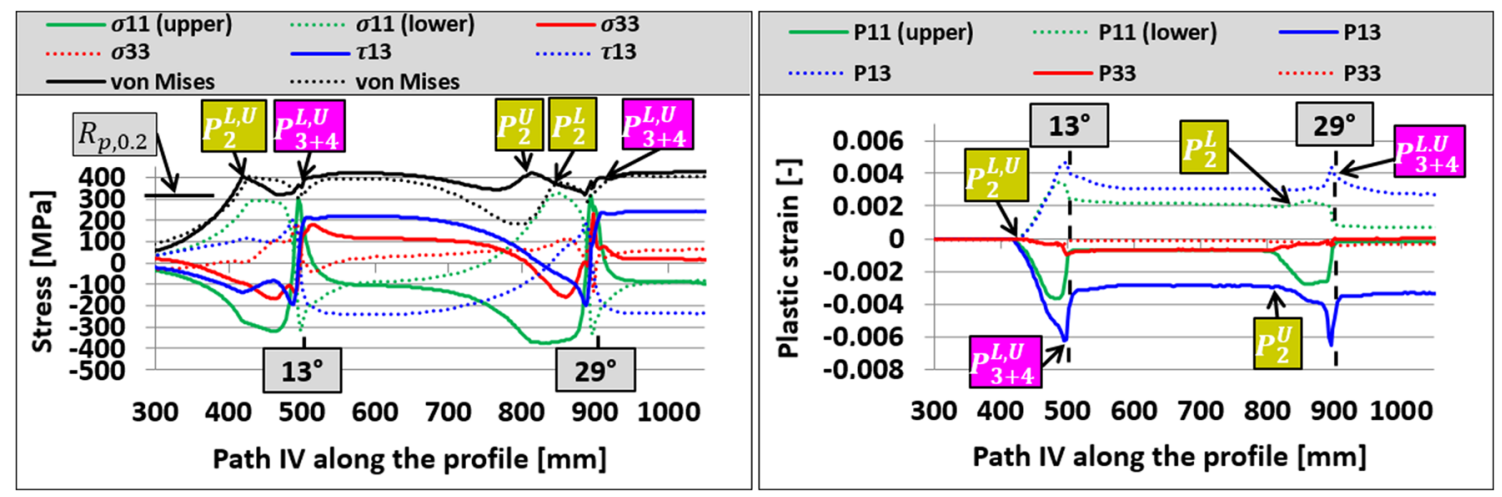

Fig. 11 Plastic strain and stresses along path IV during the forming in station 1 and 2 


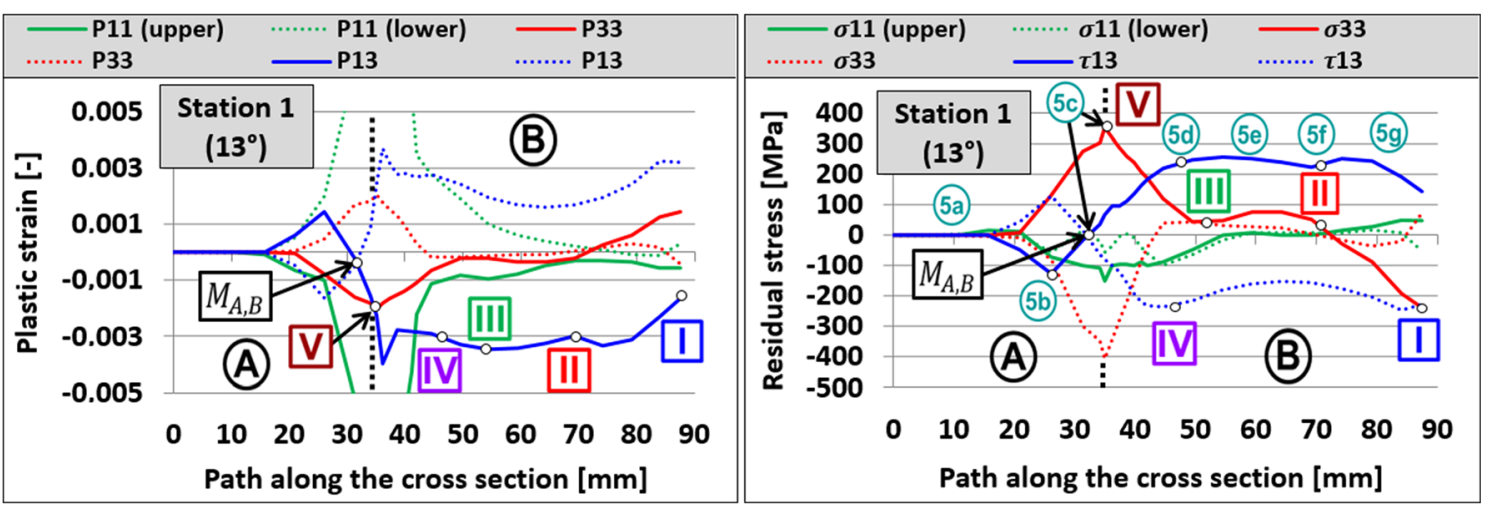

Fig. 12 Residual plastic strain and residual stresses along the cross section after station 1

shear stresses $(5 b-5 d)$. The shearing of the flange in the lower part of the flange (path IV) determines the initial level of the residual shear stresses in flange B (5d). Due to the decrease of the transversal bending load and the low longitudinal bending load as well as the low homogenous compression in the middle of the flange, the plastic shear strain decreases towards the band edge (5e). Two effects take place in the upper part of the flange $(5 f-5 g)$. On the one hand, the increasing longitudinal bending and shear loads induce higher plastic strains so that the residual shear and residual longitudinal stresses increase again (around 5f). On the other hand, the increasing homogenous longitudinal strain facilitates plastic yielding on the upper side during the reverse convex bending (see 4a, Fig. 8), which results in a stronger reduction of the plastic strains and residual stresses ( $5 \mathrm{~g}$, upper side). For this reason, the residual stresses first equally increase on the lowerand upper side, before the residual shear stresses on the upper side decrease more strongly and the residual longitudinal stresses increase less strongly than on the lower side.

\section{Parameter study}

In order to analyze the change of end flare during the forming process, end flare is measured after every forming step as shown in Fig. 13.
The numerical model is in good agreement with the experimental results, as it is able to quantitatively and qualitatively predict end flare after every forming station. In the first three stations, a slight decrease of end flare can be observed, while after station 4 there is a significant reduction of end flare as well as a greater asymmetry between lead end and tail end. The decrease is caused by the change from formgiving lower rolls to formgiving side rolls, which leads to a stronger curvature during the convex bending and convex reverse bending accompanied by a stronger reduction of plastic shear strain and residual shear stresses as well as a small increase of the plastic longitudinal strain and residual longitudinal stresses. Overall, end flare after station 1 varies by less than $1^{\circ}$. This can be attributed to the fact that, after the initial forming in the first station, increased bending and shear deformations are necessary in order to enable plastic yielding in the flange. In order to understand how the distribution of residual stresses along the cross section changes depending on the forming load, the bending angle in the first forming station is varied and the resulting residual stresses are displayed in Fig. 14.

At a bending angle of $5^{\circ}$, the curvature radius is so large and the length difference of the forming path between the band edge and the profile web so small that no plastic deformation takes place, apart from the forming of the bending zone. Therefore, small residual stresses remain in flange B near the bending zone (5e) and the resulting end flare is less than $0.5^{\circ}$.

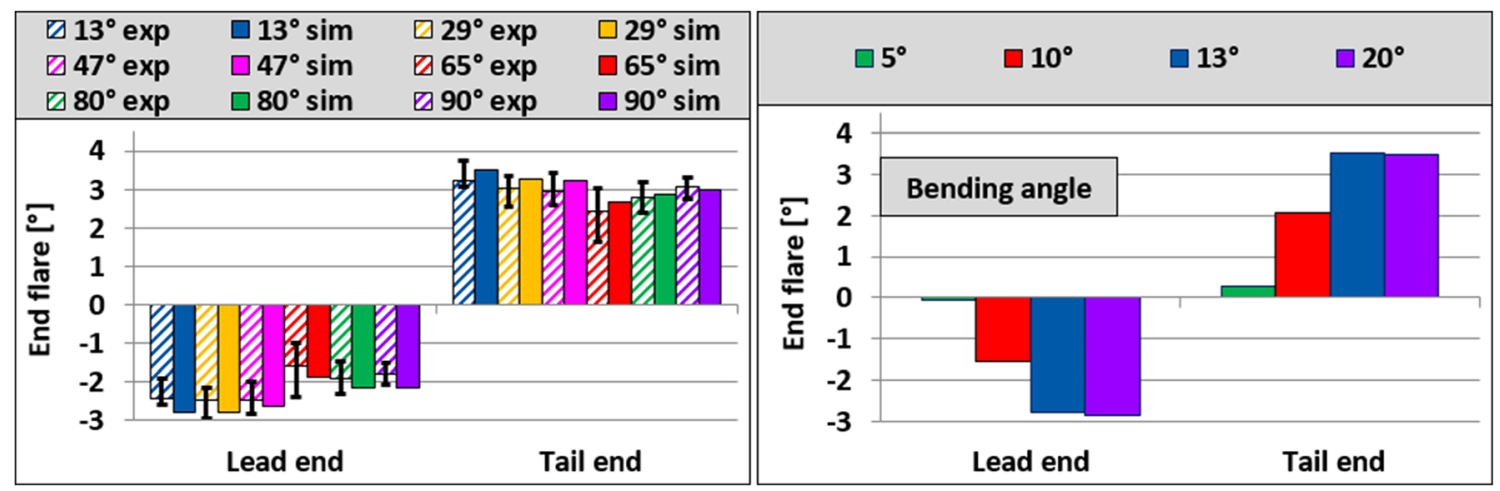

Fig. 13 End flare (experiment and simulation) after every forming station (left) and end flare (simulation) after the 1st station depending on the bending angle (right) 


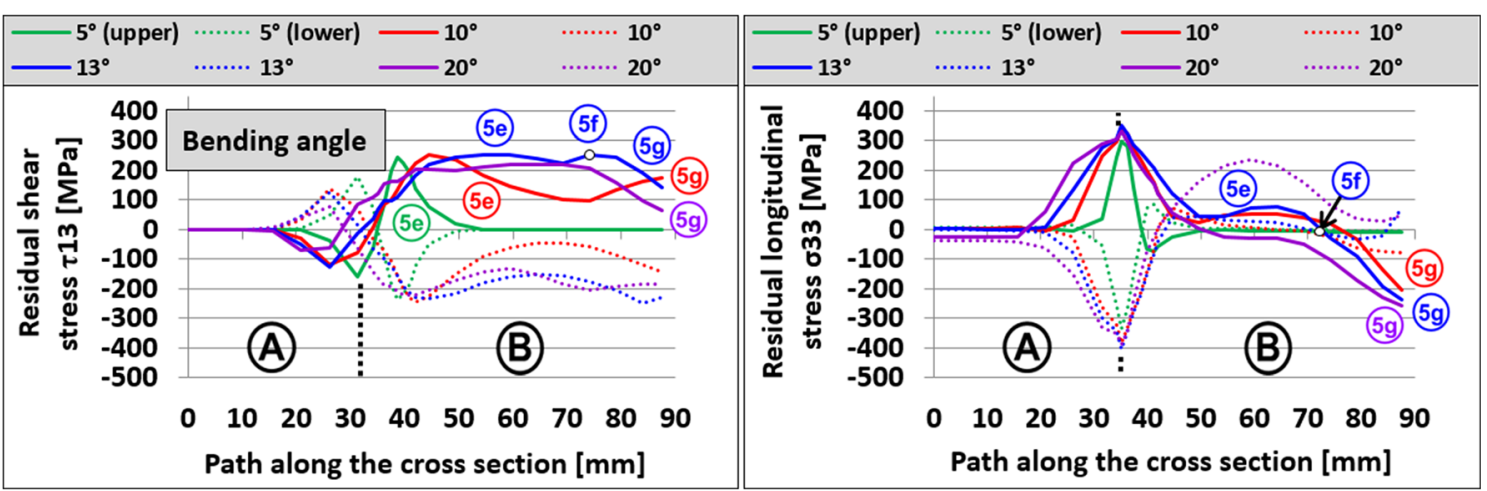

Fig. 14 Residual shear stresses and residual longitudinal stresses along the cross section after the first forming station depending of the bending angle

As the bending angle increases up to $10^{\circ}$, an increase of the shear and longitudinal residual stresses can be observed, whereby two distinct regions are created due to the change of the main bending load from transversal bending (5e) to longitudinal bending $(5 \mathrm{~g})$. The continuous increase of residual shear stresses up to the band edge $(5 \mathrm{~g})$ occurs because during the reverse convex bending the bending load is not sufficient to enable plastic yielding so that no reduction of plastic shear strains and residual shear stresses takes place. At an angle of $13^{\circ}$, as shown in Fig. 8, the residual shear stresses within the upper part of the flange ( $5 \mathrm{~g}$, upper side) decrease near the band edge (from $5 \mathrm{f}$ ), since now the bending load leads to plastic reverse convex bending and therewith reduces the plastic shear strain and residual shear stress. A further increase of the bending angle to $20^{\circ}$ results in an increase of the bending load, which leads to an increase of the residual longitudinal stresses and a stronger decrease of residual shear stresses along the whole flange $\mathrm{B}(5 \mathrm{e}-5 \mathrm{~g})$.

\section{Explanation model}

Based on the results of this study, an explanation model is developed that shows the creation as well as the remaining distribution of residual stresses that is responsible for end flare. The explanation model is shown in Fig. 15.

The model describes the forming (calibration method "constant radius") of a U-profile in which the upper rolls only have contact with the profile in the area of the web and the bending

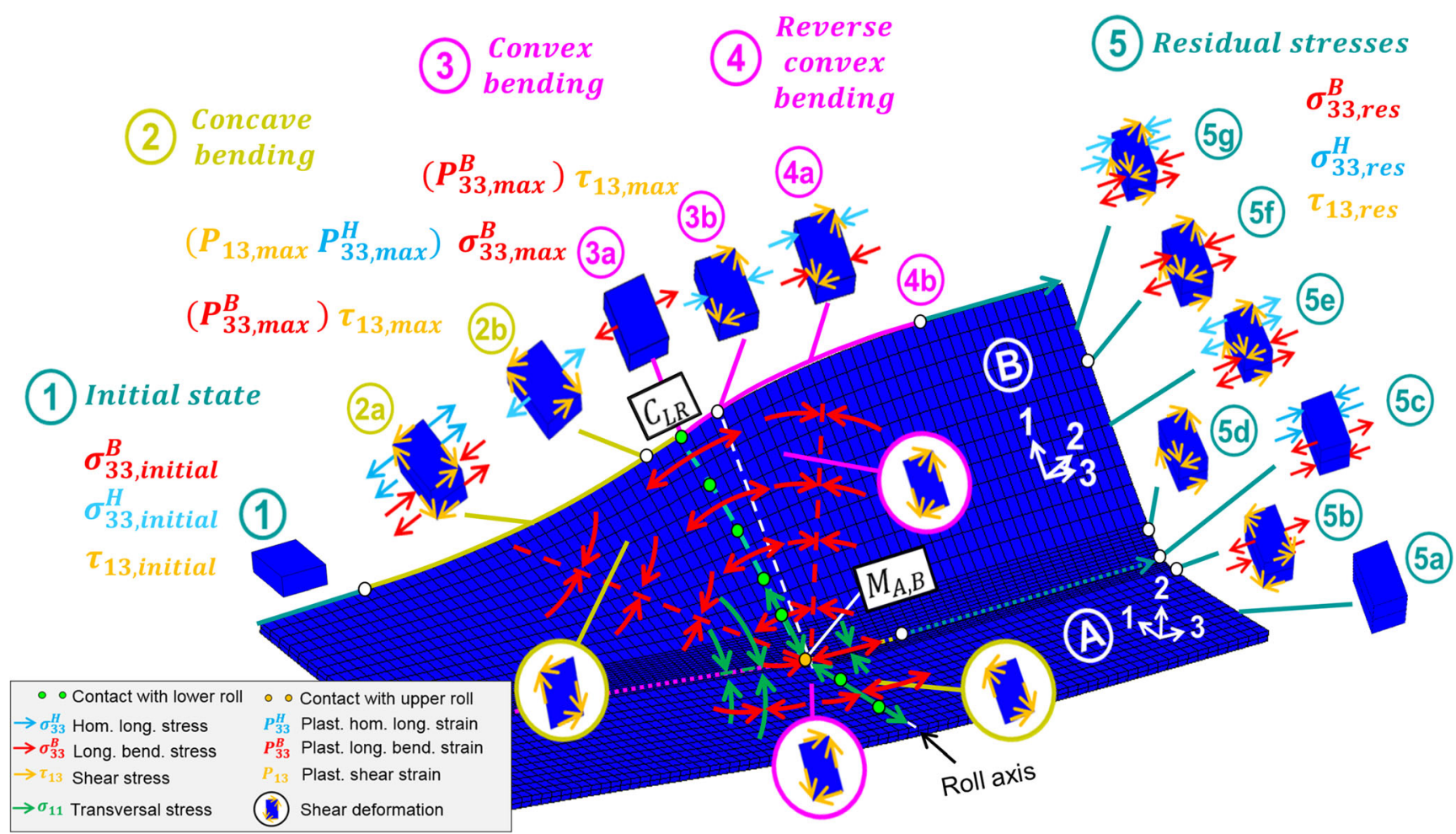

Fig. 15 Explanation model showing bending and shearing loads during roll forming as well as the creation of end flare and the remaining distribution of residual stresses along the cross section 
Fig. 16 Geometry of the Hat- and C-profile

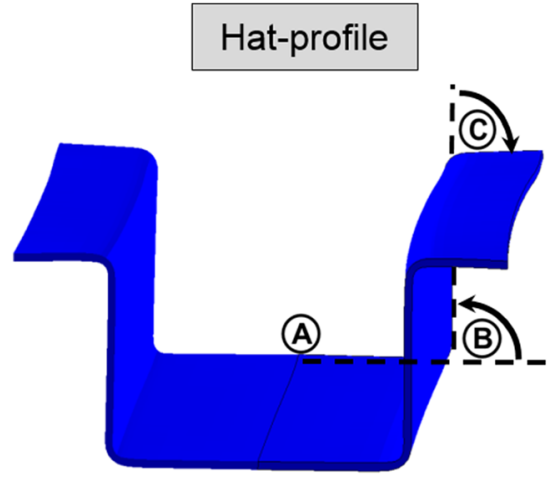

zone (see Fig. 4). Analogously to the model developed by Saffe et al. (Fig. 2), the longitudinal and transversal bending loads during roll forming in the first station are shown. Additionaly, the shear load within the profile flange and web is displayed. The forming process is divided into 5 steps, including the initial state (1) and the remaining residual stresses (5). The creation of plastic strains and residual stresses is described in detail for an element (upper side) at the band edge (compare Fig. 8), whereby the state of strains and stresses is shown at characteristic points on the concave convex forming curve. Moreover, the remaining characteristic distribution of residual stresses along the cross section is shown (compare Fig. 12 and Fig. 14). The creation mechanism (1-5) connects the forming curve with the residual stress distribution. In this way, the effect of parameter changes can be evaluated, since it is known how changes of the forming curve affect the creation of plastic strain and residual stresses.

The following assumptions and simplifications apply to the model:

- Initial stresses in the sheet are zero

- The homogenous longitudinal stresses act over the entire cross section, but are only depicted for the individual elements at the band edge

- Transversal stresses are only depicted around the bending zone

- In each of the forming steps (2, 3 and 4), plastic yielding occurs at the band edge

- Along the cross section $(5 \mathrm{a}-5 \mathrm{~g})$ only residual shear and residual longitudinal stresses are shown
- During the forming in the first station, no plastic strains occur in the profile web (5a)

\section{Analysis of the creation of residual stresses for a hat- and a C-profile}

After analyzing roll forming of a single flange, in this section simultaneous forming of two flanges is investigated. The geometries of the investigated Hat- and Cprofiles are shown in Fig. 16, whereby an additional flange with a length of $25 \mathrm{~mm}$ and a bending radius of $3 \mathrm{~mm}$ is added to the geometry of the U-profile.

When a profile flares out, the deformation takes place against the bending direction. When it flares in, the deformation takes place in bending direction. Since end flare is calculated as the difference between the bending angles measured in the stationary zone and at the cut-off, a positive end flare always corresponds to a flaring out and a negative one always corresponds to a flaring in. To investigate the creation of end flare, end flare after the first forming station $\left(13^{\circ}\right)$ is investigated, whereby both flanges are simultaneously formed. The profile deformation during the forming of the Hat- and C-profile as well as the curvature of the forming curve and the contact distribution are shown in Fig. 17.

The forming of the Hat-profile is initiated when the sheet metal makes contact with the lower roll, whereby the whole profile flange $(\mathrm{B}+\mathrm{C})$ is raised and formed along a concave forming curve. Due to the following
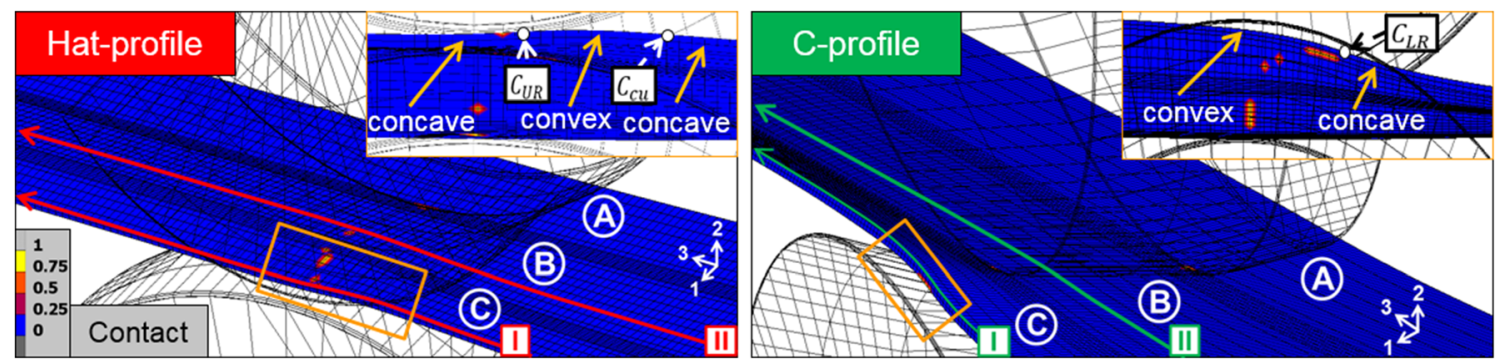

Fig. 17 Curvature of the forming curve and contact distribution within the forming zone when roll forming a Hat- and C-profile 

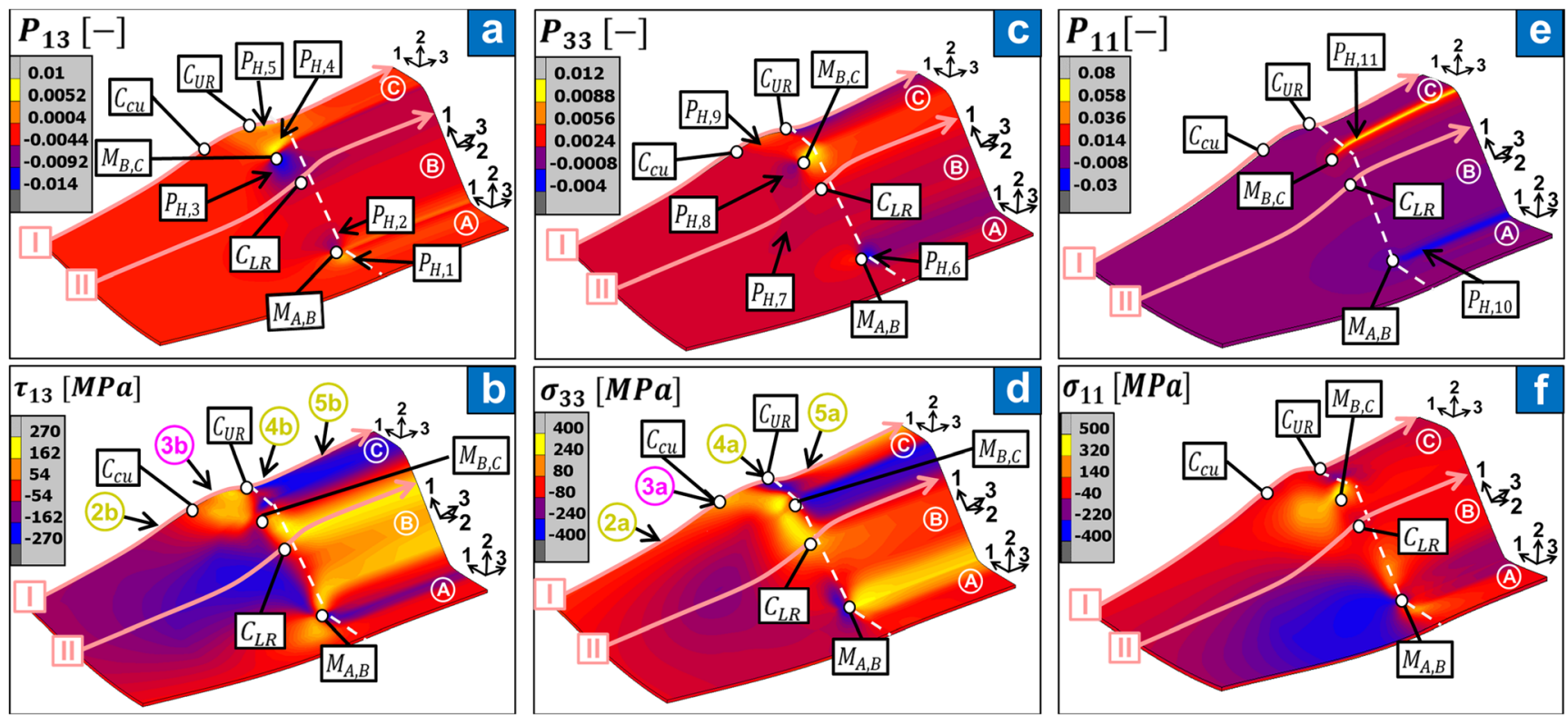

Fig. 18 Plastic shear (a), longitudinal (c) and transversal (e) strains as well as shear (b), longitudinal (d) and transversal (f) stresses during the forming of a Hat-profile in the first station (visible deformation scaled up)

contact with the upper roll, flange $\mathrm{C}$ is bent downwards in opposite direction to flange $\mathrm{B}$ and is guided into the roll gap. As a consequence, the curvature of the forming curve changes from concave to convex $\left(C_{C U}\right)$, before the flange is formed along a convex concave forming curve. The change of the longitudinal bending stress occurs at the contact line with the upper roll $\left(C_{U R}\right)$ just before the roll gap. Flange $\mathrm{B}$ is bent along a concave convex forming curve similar to the U-profile, although the forming curve is influenced by the bending of flange $\mathrm{C}$ and the contact with the upper and lower roll on both sides.

When the C-profile is roll formed, the whole flange (B + C) is initially raised due to the contact with the lower roll and bent with a concave curvature, before the upper roll guides flange $\mathrm{B}$ into the roll gap, while flange $\mathrm{C}$ is bent further upwards. Flange $\mathrm{B}$ and flange $\mathrm{C}$ are both formed along a concave convex forming curve.

\section{Hat-profile}

The distribution of plastic strains and stresses during the forming of the Hat-profile in the first station is shown in Fig. 18 .

The highest plastic strains are created when the bending zones are formed $\left(P_{H, 1}, P_{H, 2}, P_{H, 3}, P_{H, 4}, P_{H, 6}, P_{H, 8}, P_{H, 10}\right.$ and $\left.P_{H, 11}\right)$ and at the band edge $\left(P_{H, 5}\right.$ and $\left.P_{H, 9}\right)$. The homogenous longitudinal stress leads to an elongation of the outer flange $\mathrm{C}$, while the inner flange $\mathrm{B}\left(P_{H, 7}\right)$ experiences a homogenous compression. Due to the opposite bending direction of the inner and outer flanges, the longitudinal and transversal stresses and plastic strains $\left(P_{H, 6}\right.$ and $P_{H, 8}$ as well as $P_{H, 10}$ and $P_{H, 11}$ ), which are induced during the forming of the bending zone, act in opposite directions. This results in shear stresses and shear strains in the same direction within flange B $\left(P_{H, 2}\right.$ and $\left.P_{H, 3}\right)$. Plastic strains and stresses along path $\mathrm{I}$ are shown in Fig. 19.
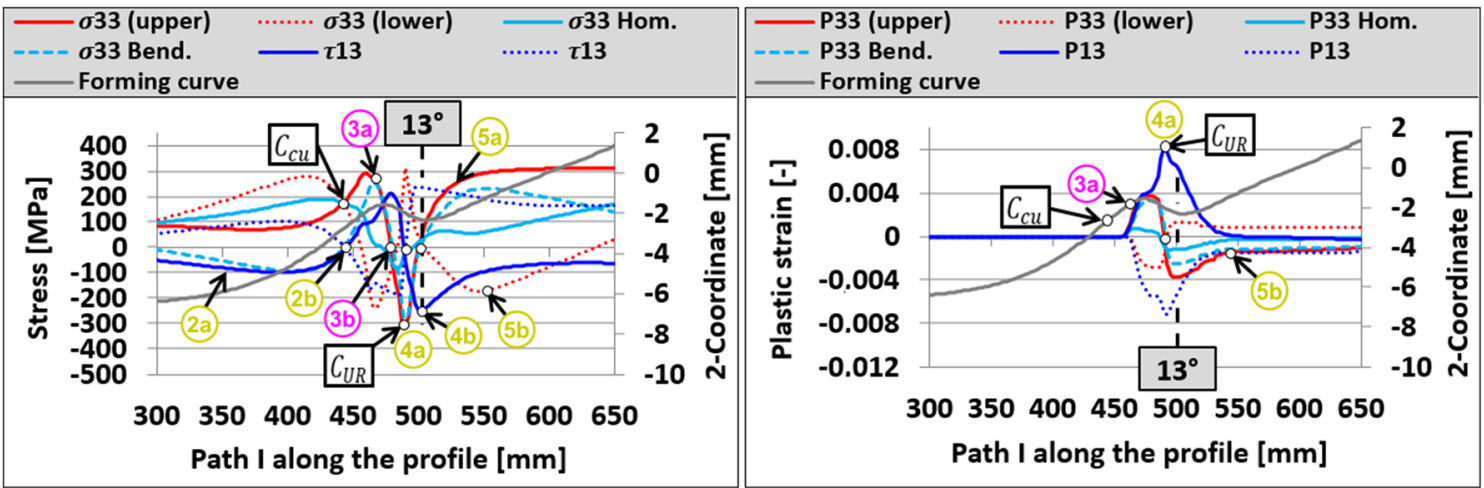

Fig. 19 Plastic strains and stresses during the forming along path I 


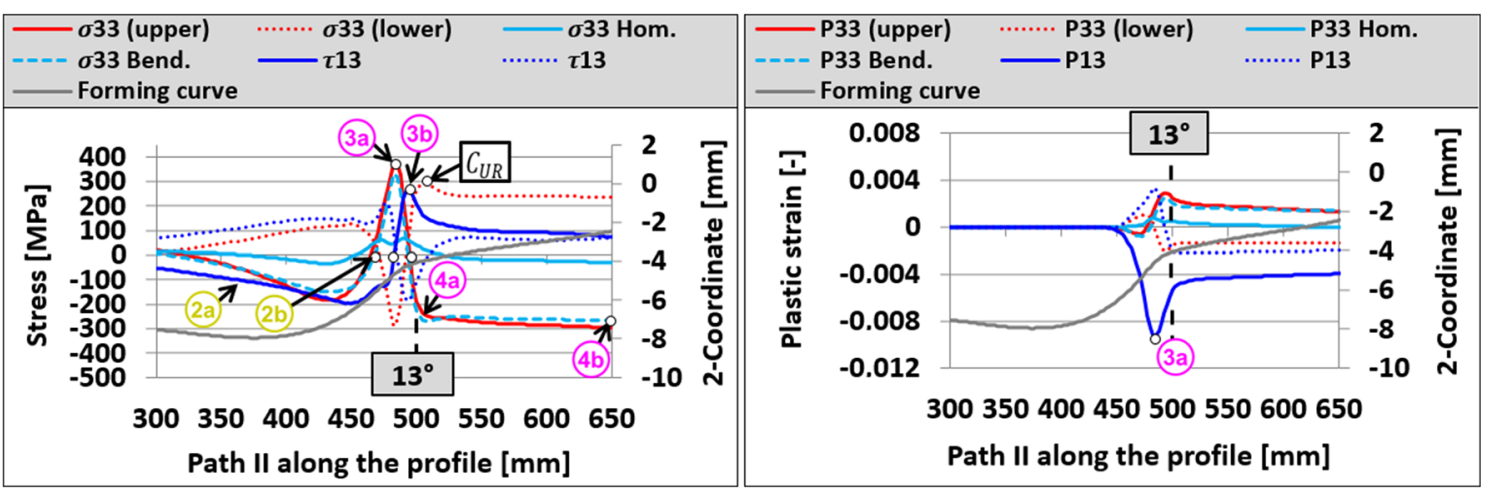

Fig. 20 Plastic strains and stresses during the forming along path II

When flange $\mathrm{B}$ and flange $\mathrm{C}$ are bent together at the beginning of the forming, the homogenous longitudinal stress that increases with the flange length (here $\mathrm{B}+\mathrm{C}$ ) cannot compensate for the simultaneously decreasing shear and longitudinal bending stresses. As a result, the deformation of the flange during the concave bending (2a) remains elastic. Therefore, the shear stress and the longitudinal bending stress change their direction at the same time (2b). The shear and longitudinal bending loads are significantly higher during the following convex concave bending due to the stronger curvature of the flange, which leads to continuous plastic deformation.

The longitudinal bending stress reaches a local maximum during the convex bending (3a) as well as after the change of direction (3b) during the concave bending (4a) at the contact point with the upper roll $\left(C_{U R}\right)$. The reverse concave bending leads again to a directional change (4b) and induces opposite directed longitudinal bending stresses (5a). The homogenous longitudinal stress changes its direction from positive to negative when the curvature changes from concave to convex (3a) and back again when the curvature becomes concave again (4a). With the beginning of plastic yielding, there is again the relationship between shear and longitudinal bending stresses in which the shear stress reaches its maximum when the longitudinal bending stress changes its direction $(3 b, 4 b)$ and the shear stress changes its direction at the point of the maximum longitudinal bending stress (4a). During the concave bending (4a) and the reverse concave bending (5a), the plastic shear strain that was induced during the convex bending (3a) and the plastic longitudinal bending strain induced during the concave bending (4a) are partly reduced. Plastic strains and stresses along path II are shown in Fig. 20.

When the bending zone of flange $\mathrm{C}$ is formed, besides the transversal bending, the sheet is convexly bent in longitudinal direction $\left(P_{H, 8}\right)$ and sheared within the sheet plane $\left(P_{H, 3}\right.$ and $\left.P_{H, 4}\right)$. As a consequence of this, after the initial concave bending of flange $\mathrm{B}+\mathrm{C}$, the longitudinal bending load and the shear load in the upper part of flange B are increased during the concave and convex bending. The contact with the upper roll also slightly increases the curvature of the forming curve in the upper area of the flange so that overall
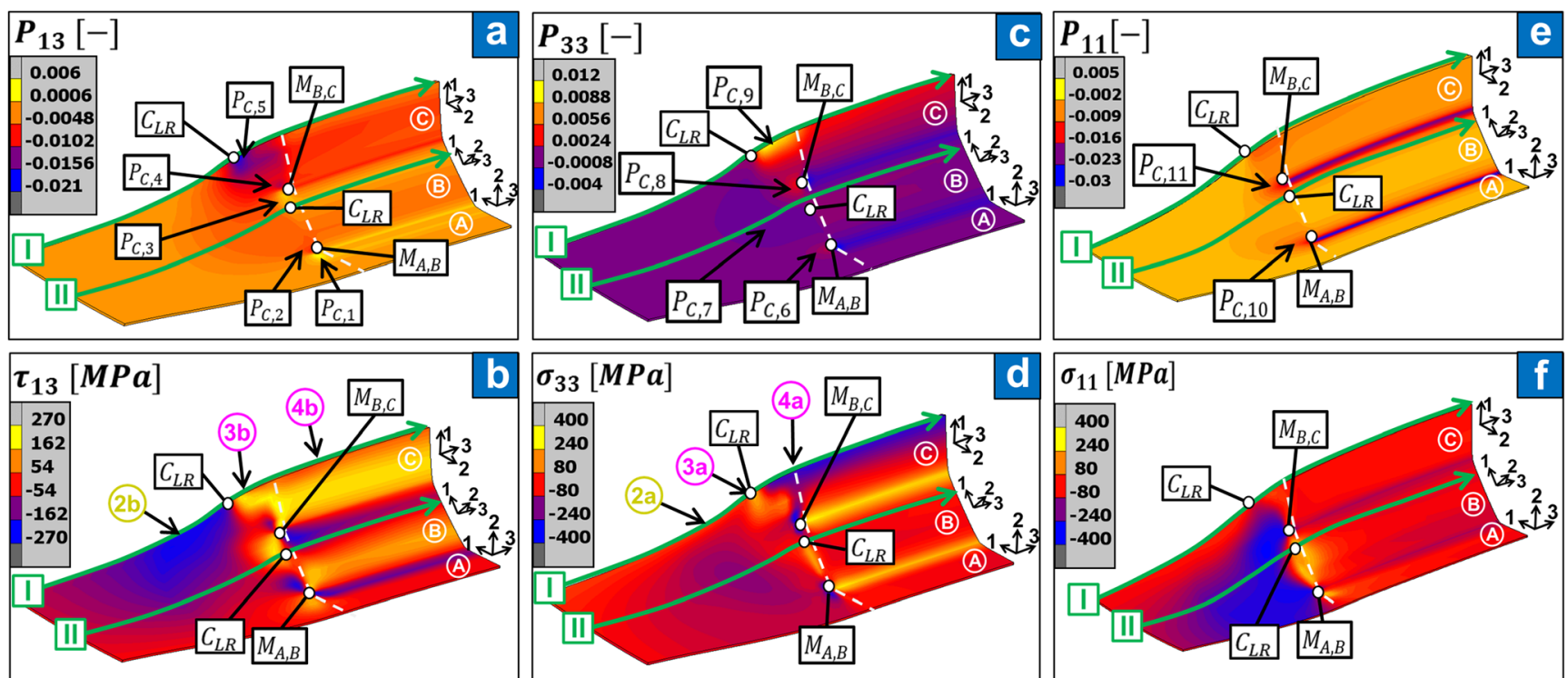

Fig. 21 Plastic shear (a), longitudinal (c) and transversal (e) strains as well as shear (b), longitudinal (d) and transversal (f) stresses during the forming of a $\mathrm{C}$-profile in the first station (visible deformation scaled up) 


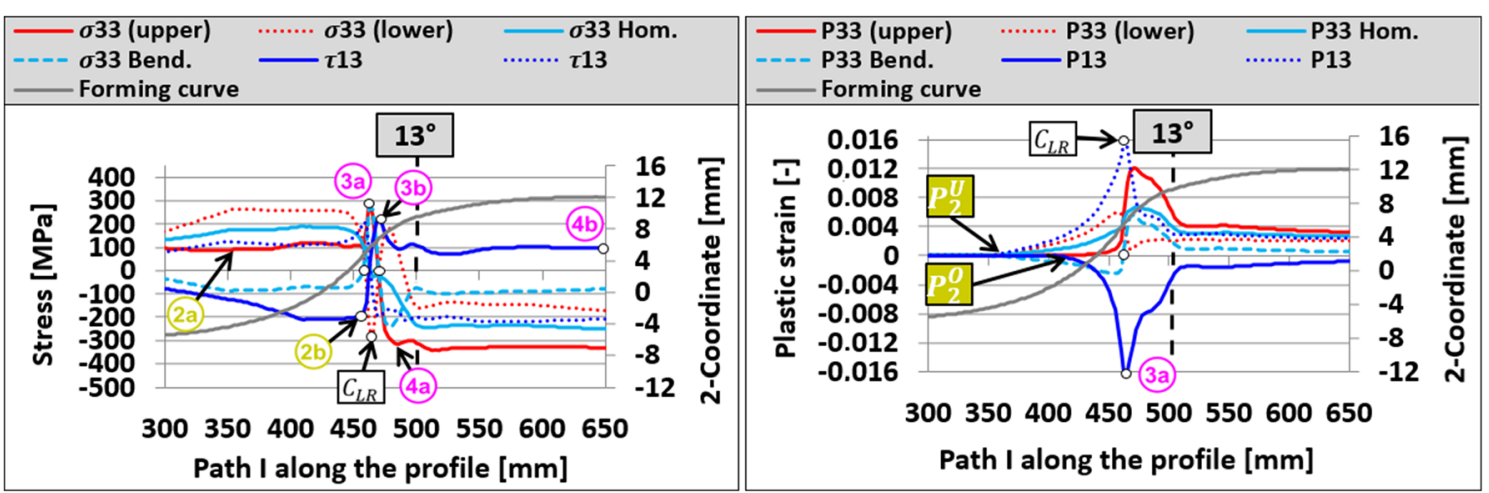

Fig. 22 Plastic strains and stresses along path I during the forming of the C-profile in station 1

the reduction of plastic shear strain (from 3a) increases and the residual shear stresses decrease. The reinforcement of the convex bending (3a) through the forming of the bending zone, on the other hand, leads to an increase of residual longitudinal stresses. Transversal stresses have no significant influence on the shear stress along path II (see Fig. 18).

\section{C-profile}

The distribution of plastic strains and stresses during the forming of the C-profile in the first station is shown in Fig. 21.

Since both flanges are bent in the same direction, the highest plastic strains occur at the band edge $\left(P_{C, 5}\right.$ and $\left.P_{C, 9}\right)$. In order to compensate for the longitudinal tensile strains at the band edge, longitudinal compressive strains are induced in the flange $\left(P_{C, 7}\right)$. The plastic longitudinal and transversal strains that are induced when the two bending zones are formed $\left(P_{C, 6}, P_{C, 8}, P_{C, 10}\right.$ and $\left.P_{C, 11}\right)$ act in the same direction. As a result, shear strains and stresses in opposite direction $\left(P_{C, 2}\right.$ and $\left.P_{C, 3}\right)$ occur in the upper and lower part of flange B. Plastic strains and stresses along flange C (path I) are shown in Fig. 22.

During the concave bending (2a), the homogenous longitudinal stress causes a strongly asymmetrical beginning of plastic yielding. As a result of the in comparison to the Uprofile significantly higher shear and longitudinal bending stresses, the flange is continuously plastically deformed. Analogous to the U-profile, significant plastic shear and longitudinal strains and therewith significant residual shear and residual longitudinal stresses remain, whereby the homogenous component prevails. Plastic strains and stresses along flange B (path II) are shown in Fig. 23.

When the bending zone of flange $\mathrm{C}$ is formed, besides the transversal bending, the sheet is concavely bent in longitudinal direction $\left(P_{C, 8}\right)$ and sheared within the sheet plane $\left(P_{C, 3}\right.$ and $\left.P_{C, 4}\right)$. These shear stresses act opposite to the shear stresses induced by the concave bending of flange B. Furthermore, due to the aligned transversal bending of flange $\mathrm{B}$ and $\mathrm{C}$, high transversal stresses are induced in the upper part of flange B when the bending zone of flange $\mathrm{C}$ is formed (see Fig. 21). As a consequence, the transversal bending stress mainly is responsible for the creation of shear stress in the upper part of flange $B(3 a-5 a)$.

Therefore, after the initial concave bending of flange $\mathrm{B}+\mathrm{C}$, the shear stress changes its direction when the transversal bending stress reaches a local maximum (3a) and then again at the contact point with the upper roll (4a). The plastic shear strain, which is induced during the concave bending, is completely removed due to the increased convex bending load. After the following reverse convex bending significant residual stresses and plastic strains remain in the sheet.
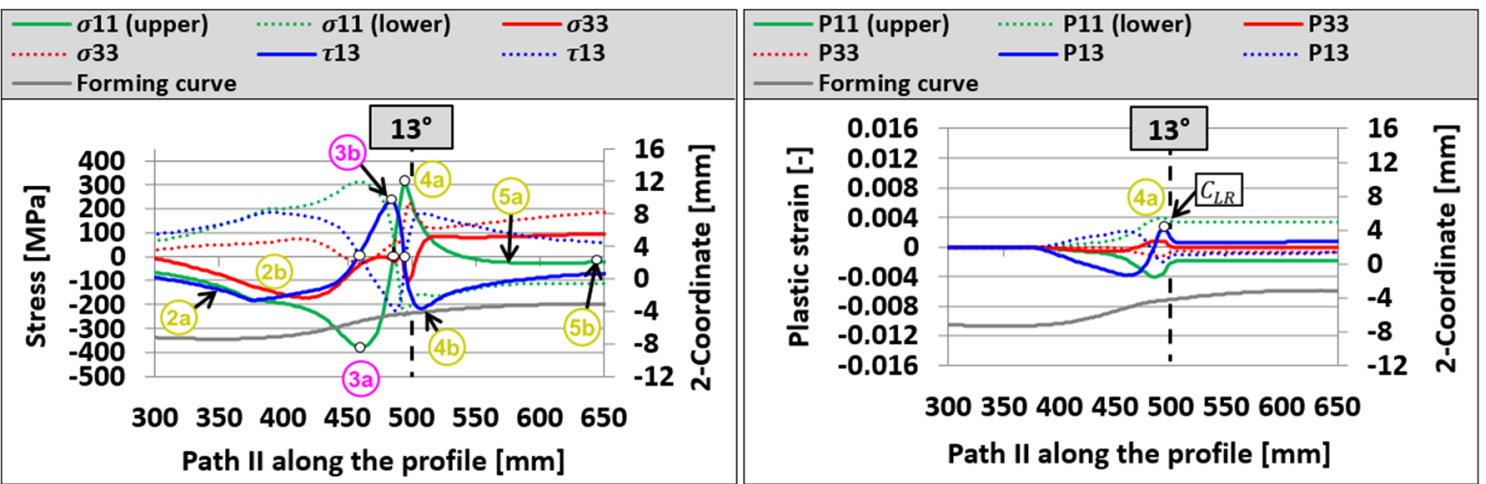

Fig. 23 Plastic strain and stresses along path II during the forming of the C-profile in station 1 


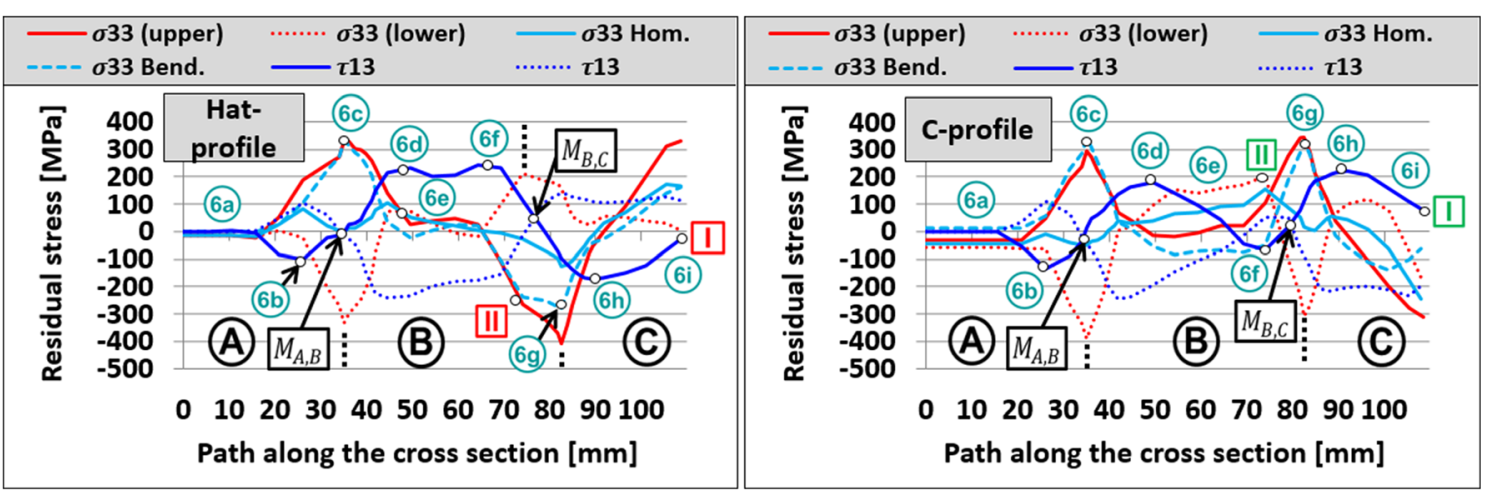

Fig. 24 Distribution of residual stresses along the cross section for the Hat-profile (left) and C-profile (right) after the first forming station

\section{Distribution of residual stresses along the cross section}

The distribution of residual stresses along the cross section of the Hat- and C-profile is shown in Fig. 24.

The characteristic distribution induced by the forming of the bending zone of flange B $(6 a-6 d)$ is the same for all profile variants (U-, C- and Hat-profile). From this point on, the distributions of residual stresses of the Hat- and C-profile differ.

Hat-profile Residual shear and residual longitudinal stresses in flange B are comparable to the residual stresses of the U-profile, which means that there initially is a decrease of the shear stress (6e), before the shear stress increases again with increasing longitudinal bending load (6f). Due to the forming of the bending zone of flange $\mathrm{C}$, the convex curvature and the reduction of the convex curvature in the upper part of flange $\mathrm{B}$ are increased. Therefore, stronger residual longitudinal stresses and lower residual shear stresses remain $(6 f-6 g)$. Corresponding to the opposite directed deformation of flange $\mathrm{C}$, the residual shear stresses change direction $(6 \mathrm{~g})$ in the middle of the bending zone, initially increase (6h) and then decrease again due to the increasing shear and longitudinal bending stress towards the band edge (6i). The residual longitudinal stresses reach their maximum in the middle of the bending zone $(6 \mathrm{~g})$ and change direction (6h) in flange $\mathrm{C}$ according to the longitudinal bending load. Due to the strong homogenous part, tensile residual longitudinal stresses remain at the upper and lower side.
Saffe et al. also investigate the residual shear stresses within a Hat-profile, but find in contrast to this investigation a directional change of the residual shear stresses in the upper part of flange B (around 6f) [24, 26]. Regarding the stresses during the forming process [24], within their investigation the shear stresses in the upper part of the longer, inner flange change their direction during the reverse convex bending (unlike Fig. 20). This change of direction is limited to the area in which the flange has contact with the upper roll. Therefore, one possible reason can be a stronger curvature of the forming curve of flange $\mathrm{B}$ during the convex bending and reverse convex bending due to contact with the upper roll. The change of curvature is significantly stronger when the stiffness of the forming station is not considered in the numerical model. Thus, the results of Saffe et al. do not contradict the results within this study, but can be explained by a locally stronger deformation during the reverse convex bending.

C-profile Due to the higher longitudinal bending load, significant longitudinal residual stresses remain within flange $\mathrm{B}$ and because of the high transversal bending load near the bending zone of flange $\mathrm{C}$, the residual shear stresses decrease along the whole flange (6e). Since flange B and $\mathrm{C}$ are subjected to transversal bending in the same direction, the state of residual stresses within the bending zone of flange $C(6 f-6 h)$ is the same as in the bending zone of flange $B(6 b-6 d)$.
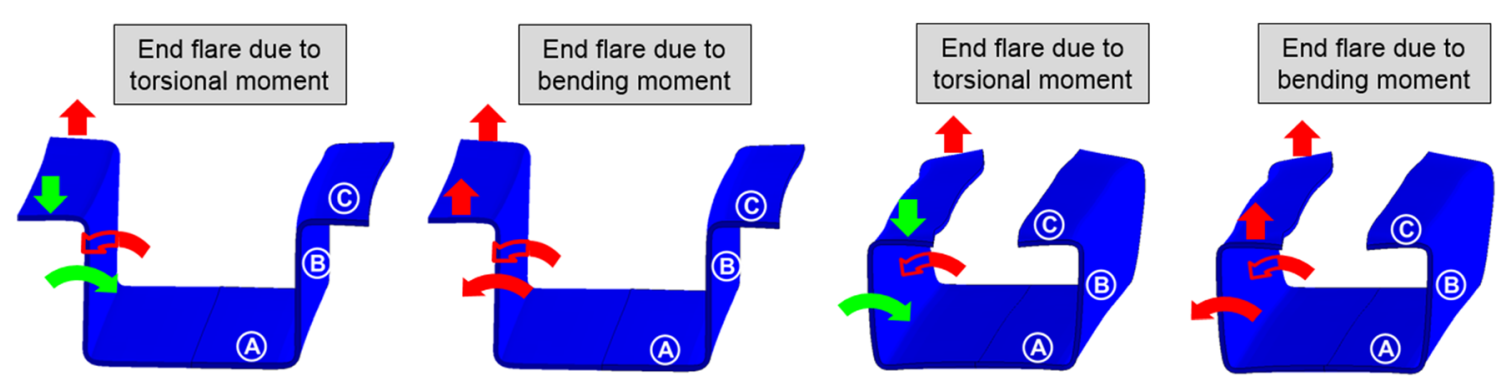

Fig. 25 Direction of end flare due to the release of shear and longitudinal residual stresses of a Hat-profile (left) and a C-profile (rights) 


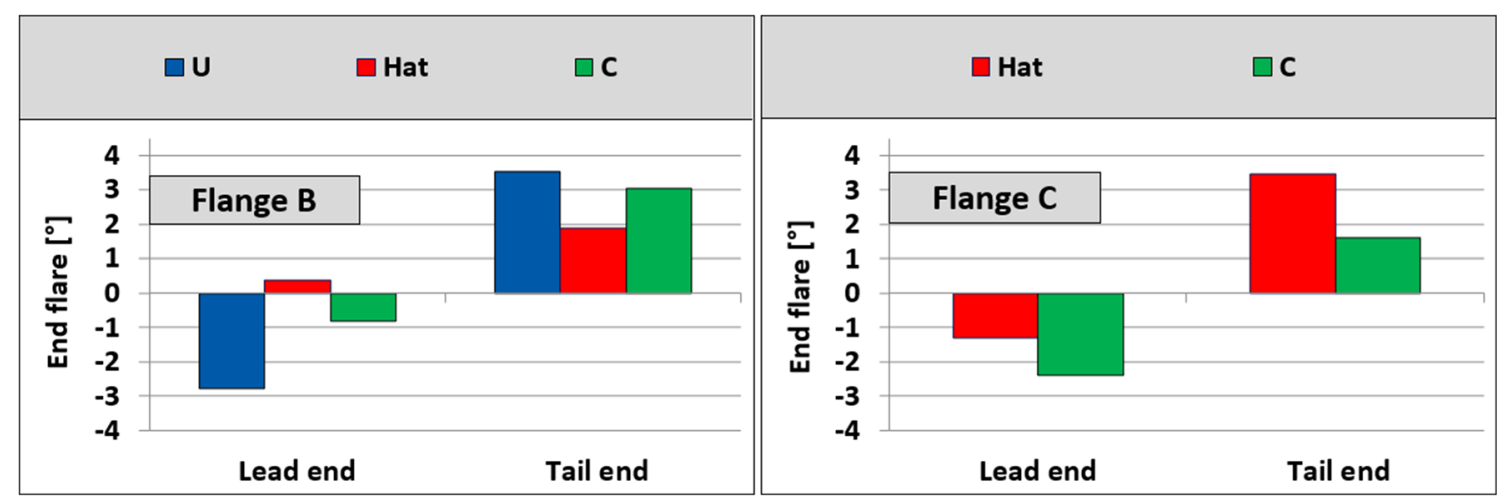

Fig. 26 End flare (simulation) after the first forming step for a U-, Hat- and C-profile

In flange $\mathrm{C}$ the characteristic stress distribution after the forming of an outer flange in which the residual shear stresses decrease towards the band edge and the residual longitudinal stresses have a significant homogenous part and a significant bending part remains. When forming a C-profile, the homogenous part dominates, while when forming a Hat-profile the bending part prevails.

\section{End flare}

The direction of the profile deformation due to the released torsional and bending moments can be derived from the distribution of the shear and longitudinal residual stresses and are shown in Fig. 25.

The superposition of the individual moments determines the moment, which acts on the flange when the profile is cut. Figure 26 shows the end flare after the 1 st forming station $\left(13^{\circ}\right)$.

Flange B of the U-profile has the strongest end flare among all investigated profile types.

\section{Hat-profile}

If the Hat-profile is cut, the release of the residual stresses creates torsional and bending moments that act on flange $\mathrm{B}$ and flange $\mathrm{C}$ in opposite directions. In contrast to the $\mathrm{U}$ - profile, a weaker torsional moment and a stronger bending moment act on flange B so that it flares out at both ends. The torsional moment is weaker because, on the one hand, the torsional moment in flange $\mathrm{C}$ counteracts it and on the other hand, the residual shear stresses in the upper part of flange $B$ are lower. In contrast, the residual longitudinal stresses increase in the upper part of flange $B$ due to the forming of the second bending zone. This creates a bending moment that outweighs the opposite bending moment of flange $\mathrm{C}$ and causes both sides to flare out.

The end flare of flange $\mathrm{C}$ is characterized by a flaring in at the lead end and a flaring out at the tail end, whereby end flare is shifted in positive direction (flaring out) due to the bending moment. This end flare is characteristic for the roll forming of outer flanges and also occurs when roll forming U-profiles.

C-profile When the C-profile is cut, only a small torsional moment acts on flange $\mathrm{B}$ due to the directional change of the shear stresses along the flange (Fig. 24). However, the torsional moment is reinforced by the torsional moment acting on flange $\mathrm{C}$, since both moments act in the same direction. In the same way, the bending moments in flange $\mathrm{B}$ and flange $\mathrm{C}$ are superimposed. After the first station, the superimposed bending moment is not high enough in order to create a flaring out at both ends of flange $\mathrm{B}$, which is the characteristic end flare for C-profiles after the final geometry is reached. Instead,



Fig. 27 End flare (simulation) of a Hat- and C-profile depending on the flange length of the outer flange C 


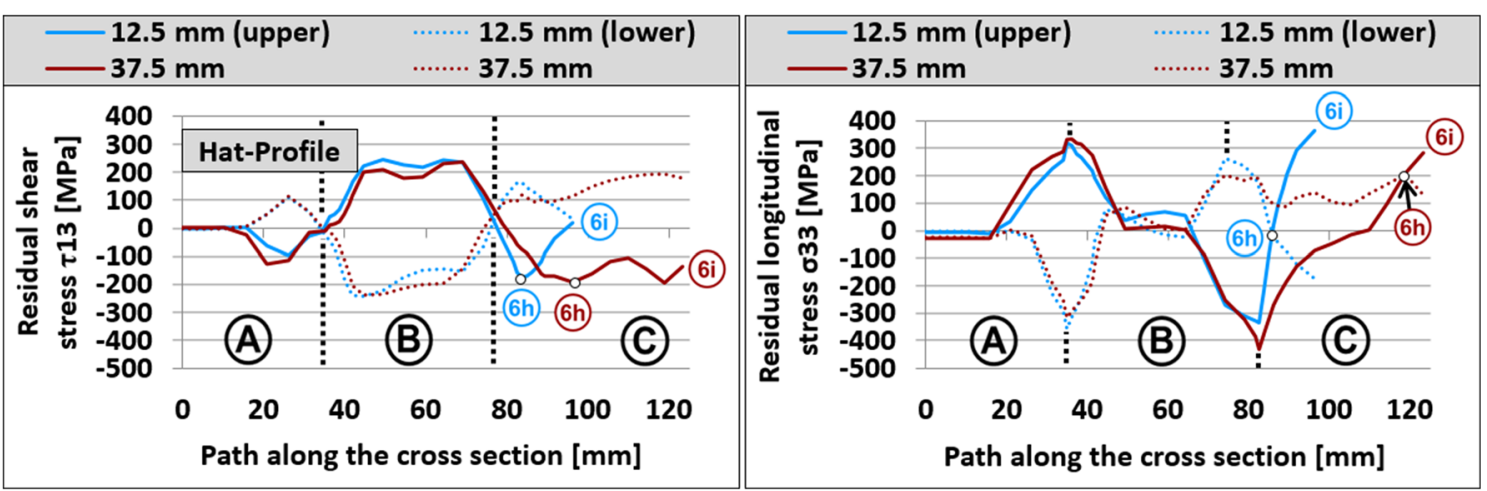

Fig. 28 Distribution of residual stresses along the cross section of the Hat-profile depending on the flange length

there is a slight flaring in at the lead end and a strong flaring out at the tail end. Regarding flange $\mathrm{C}$ the end flare is comparable to the U-profile, where flange $\mathrm{C}$ flares in at the lead end and flares out at the tail end. The fact that the end flare is shifted in negative direction (flaring in), although the bending moment causes a flaring out at both sides according to the longitudinal residual stresses, can be explained by the deformation of flange B. Flange B experiences only a very slight deformation at the lead end and therefore acts as a bending edge for flange $\mathrm{C}$. On the contrary, at the tail end flange $\mathrm{B}$ and flange $\mathrm{C}$ flare out at the same time so that the bending of flange $\mathrm{B}$ reduces the bending of flange $\mathrm{C}$ relative to flange $\mathrm{B}$.

\section{Parameter study}

To further study the impact of the outer flange on the end flare of the whole profile, the flange length of the outer flange $\mathrm{C}$ is varied, while the length of the inner flange B remains constant. The corresponding end flare is shown in Fig. 27.

In general, it can be observed that the end flare of flange $\mathrm{C}$ increases with the flange length, while the change of end flare of flange $\mathrm{B}$ depends on the bending direction of flange $\mathrm{C}$, whereby lower deformations can be observed for the Hatprofile and higher deformations for the C-profile.

Hat-profile The distribution of residual stresses along the cross section of the Hat-profile is shown in Fig. 28.
It can be seen that the residual stresses in flange B are not significantly affected by the length of flange $C$. Regarding flange $\mathrm{C}$, the reduction of the plastic shear strains during the reverse concave bending decreases with increasing flange length and larger residual shear stress remain in flange $C(6 \mathrm{~h}, 6 \mathrm{i})$. Furthermore, the homogenous part of the longitudinal residual stress increases, whereas the bending part decreases (6h, 6i). For a flange length of $37.5 \mathrm{~mm}$, the residual longitudinal stresses on the lower side do not change their direction within flange $\mathrm{C}$ because the plastic deformation during the concave bending (4a, Fig. 19) is not strong enough to remove the plastic strains induced during the convex bending. Overall, end flare of flange $\mathrm{C}$ increases with increasing length due to the stronger torsional moment acting on the flange. The change of the bending moment depends on whether the increased lever arm of the moment or the reduced bending stresses have a stronger impact. Regarding flange $\mathrm{B}$, since the torsional moment in flange $\mathrm{C}$ increases, the resulting torsional moment that causes the deformation of flange $\mathrm{B}$ is reduced so that the end flare at the lead end changes its direction and both ends flare out. The reduction of end flare at the tail end is less than the increase at the lead end (after the directional change) due to a stronger bending moment acting on flange B.

C-profile In contrast, looking at the C-profile, the residual stresses within flange $\mathrm{B}$ are affected when the length of flange C increases as shown in Fig. 29.
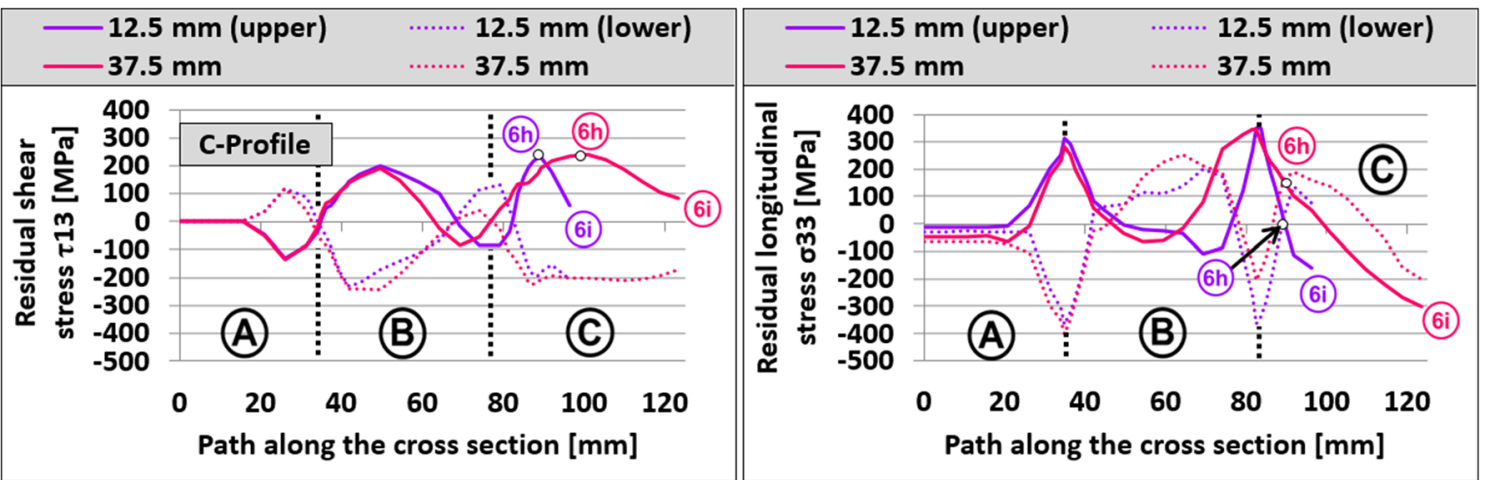

Fig. 29 Distribution of residual stresses along the cross section of the C-profile depending on the flange length 
Table 1 Typical bending angle sequence of a C-profile

\begin{tabular}{lllllllllll}
\hline C-profile & 1. & 2. & 3. & 4. & 5. & 6. & 7. & 8. & 9. & 10. \\
\hline Forming & $\mathrm{C}$ & $\mathrm{C}$ & $\mathrm{C}$ & $\mathrm{B}$ & $\mathrm{B}$ & $\mathrm{B}$ & $\mathrm{B}$ & $\mathrm{B}+\mathrm{C}$ & $\mathrm{B}+\mathrm{C}$ & $\mathrm{B}+\mathrm{C}$ \\
Bending angle flange $\mathrm{B}\left[^{\circ}\right]$ & $0^{\circ}$ & $0^{\circ}$ & $0^{\circ}$ & $13^{\circ}$ & $29^{\circ}$ & $47^{\circ}$ & $65^{\circ}$ & $75^{\circ}$ & $85^{\circ}$ & $90^{\circ}$ \\
Bending angle flange $\left.\mathrm{C}^{\circ}\right]$ & $15^{\circ}$ & $40^{\circ}$ & $65^{\circ}$ & $65^{\circ}$ & $65^{\circ}$ & $65^{\circ}$ & $65^{\circ}$ & $75^{\circ}$ & $85^{\circ}$ & $90^{\circ}$ \\
\hline
\end{tabular}

With increasing flange length, there is a slight reduction of residual shear stresses and a significant increase of residual longitudinal stresses in flange $\mathrm{B}$, whereby the latter is a result of the balance of longitudinal stresses along the cross section. The significant increase of the torsional moment in flange $\mathrm{C}$ $(6 \mathrm{~h}, 6 \mathrm{i})$ outweighs the decrease of the torsional moment in flange $\mathrm{B}$ so that the flaring in at the lead end and the flaring out at the tail end of flange $\mathrm{C}$ and flange $\mathrm{B}$ are both increased. The increased bending moment acting on flange B causes a stronger flaring out. In contrast to the Hat-profile, the increase of the bending moment is not enough to change the direction of end flare at the lead end. These results are in agreement with the experimental investigations regarding end flare of the inner flanges that are described in the state of the art [23, 25].

\section{Influence of the forming strategy}

Profiles with several bends can be roll formed using sequential forming or simultaneous forming of the flanges. As shown in a previous study [28], end flare of Hat-profiles does vary significantly depending on the bending angle sequence because of the opposite directed moments acting on flange B and C. While Hat-profiles usually are simultaneously formed in order to minimize the number of forming steps, C-profiles are formed by a combination of sequential and simultaneous forming. The reason for this is that during simultaneous forming, the outer flange experiences an increased elongation, which can lead to the occurrence of plastic waves. Therefore, the outer flange $\mathrm{C}$ is roll formed first, before the inner flange $\mathrm{B}$ is formed, as shown in Table 1.

The corresponding end flare after stations 3, 4, 7, 8 and 10 is shown in Fig. 30.
After station 3 the typical end flare of a U-profile can be observed for flange $\mathrm{C}$. When only flange $\mathrm{B}$ is bent, flange $\mathrm{C}$ functions as an extension of flange $\mathrm{B}$ and is subjected to bending and shear deformation. Therefore, from station 4 to 7 residual stressses change within flange $\mathrm{B}$ and $\mathrm{C}$, which leads to an increasing bending moment in flange $\mathrm{B}$ and a flaring out at both profile ends. During the last three forming steps, both flanges are bent simultaneously because the forming rolls do not reach the inner side of the bending zones as shown in Fig. 31.

Without the longitudinal bending within the area of the bending zones (compare Fig. $21 P_{C, 6}$ and $P_{C, 8}$ ) the distribution of residual longitudinal stresses changes. Compared to the distribution of residual stresses after the first station (Fig. 24 $6 \mathrm{c}, 6 \mathrm{~g})$, the residual longitudinal bending stress changes its direction ( $6 b-6 d$ and $6 f-6 h)$. Since this effect is caused by the balancing out of the longitudinal stresses along the cross section, the characteristic points of the shear residual stresses do not change. Furthermore, the longitudinal residual stresses in the adjacent zones do not undergo any significant change, so the same characteristic end flare remains.

\section{Typical end flare}

As shown in Fig. 25, end flare is determined by the superposition of the torsional and bending moments that act on the inner flange $\mathrm{B}$ and the outer flange $\mathrm{C}$. Thus, the direction and the magnitude of end flare can vary depending on profile and process parameters, which can change throughout the forming steps (Fig. 30). However, there are characteristic profile deformations of the inner and outer flanges for U-, Hat- and Cprofiles, which are shown in Fig. 32.
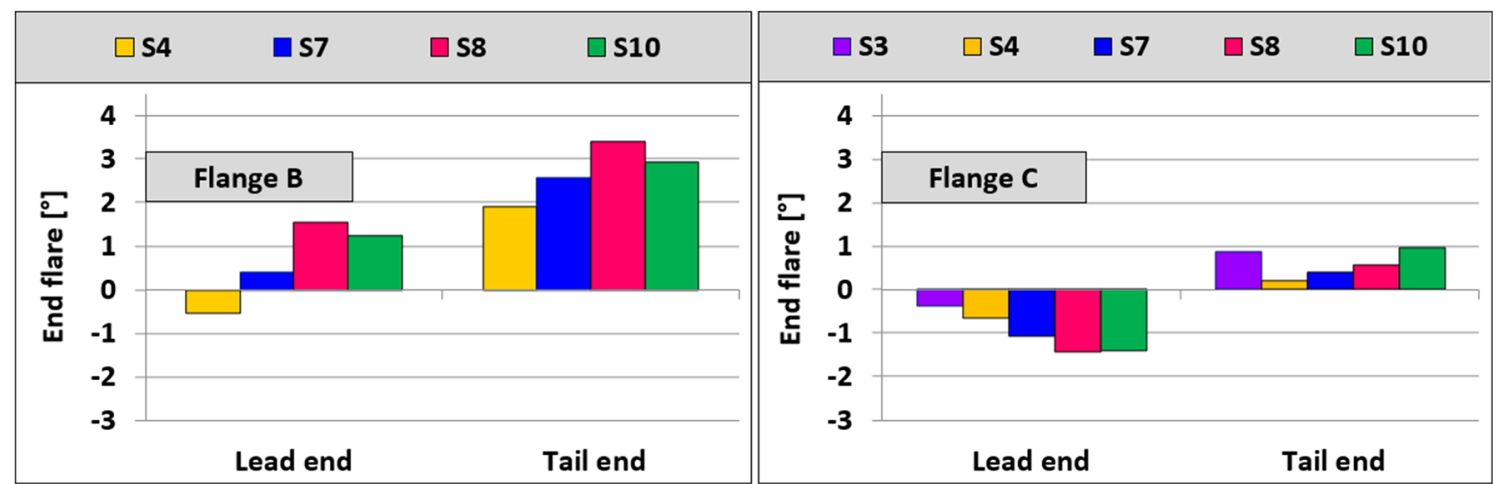

Fig. 30 End flare (simulation) of a C-profile after selected forming stations 
Fig. 31 Forming in station 10 (left) and residual stresses along the cross section after station 10 (right)

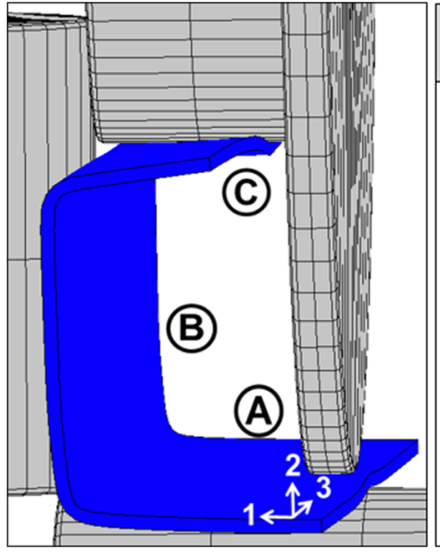

While end flare of outer flanges, which includes the flanges of the U-profile, is characterized by a flaring in and a flaring out at the profile ends, end flare of the inner flanges is usually characterized by a flaring out at both ends. In the case of a short flange length (Fig. 27) or small bending angles (Fig. 30), the torsional moment caused by the residual shear stresses in flange B (compare Fig. 25) can cause a flaring in and out at the profile ends of flange $B$.

\section{Explanation models}

Similar to the explanation model for the creation of end flare when roll forming a U-profile, additional models for the creation of end flare when roll forming a Hat-profile and a Cprofile are developed.

Hat-profile The explanation model shown in Fig. 33 displays the forming loads, the creation of residual stresses during the simultaneous forming of flange $\mathrm{B}$ and $\mathrm{C}$ (opposite bending direction) in the first station $\left(13^{\circ}\right)$ as well as the remaining distribution of residual stresses.

The creation of residual stresses in flange $\mathrm{C}$ is explained by means of the characteristic forming steps "Concave bending" (2), "Convex bending" (3), "Concave bending" (4) and "Reverse concave bending" (5) defined in Fig. 19. The characteristic forming steps during the creation of residual stresses in the upper part of flange B are described in Fig. 20.

The same assumptions, which apply to the model of the Uprofile, apply here as well. It is further assumed that the contact with the upper roll in the upper part of flange B is not sufficient to increase the convex curvature to such an extent that a change in direction of the shear stresses occurs during the reverse convex bending. In the lower part, the creation of residual stresses and the forming steps correspond to the ones of the U-profile (Fig. 11). The residual stresses across the cross section are described by characteristic points defined in Fig. 24. For simplification, it is assumed that the homogenous longitudinal stresses change direction simultaneously with the longitudinal bending stresses (6d, 6f, 6h). The deformation resulting from the release of the torsional and bending moments is shown in Fig. 25.

C-profile The explanation model shown in Fig. 34 displays the forming loads, the creation of residual stresses during the simultaneous forming of flange $\mathrm{B}$ and $\mathrm{C}$ (same bending direction) in the first station $\left(13^{\circ}\right)$ as well as the remaining distribution of residual stresses.

The same assumptions, which apply to the model of the Uprofile, apply here as well. The forming of flange $\mathrm{C}$ along the band edge is described according to the characteristic forming steps "Concave bending" (2), "Convex bending" (3),
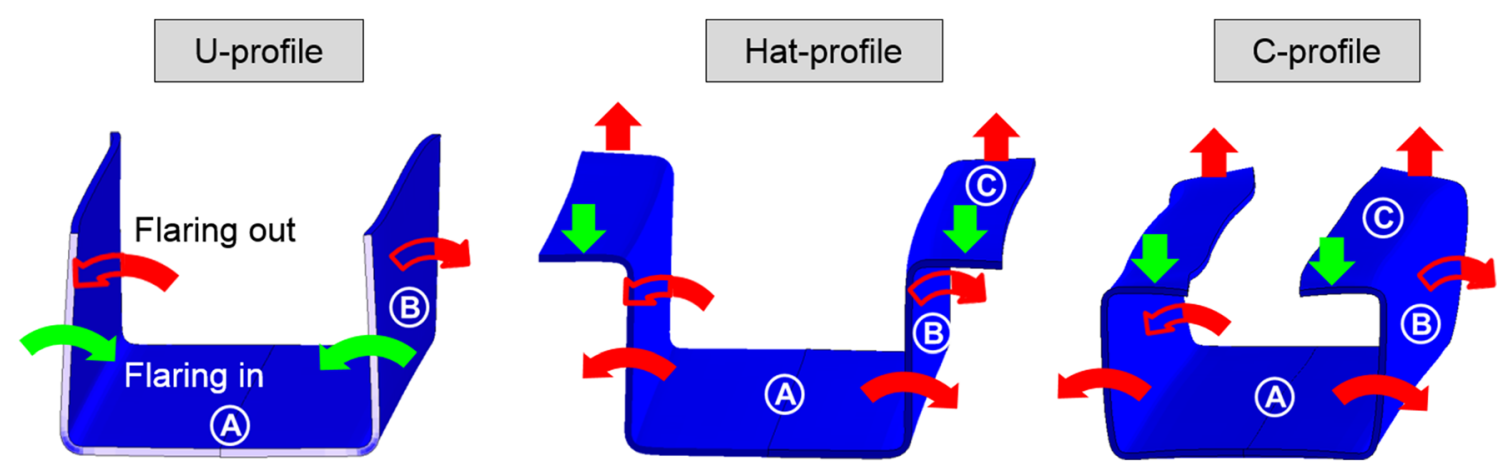

Fig. 32 Typical end flare for U-, Hat- and C-profiles 


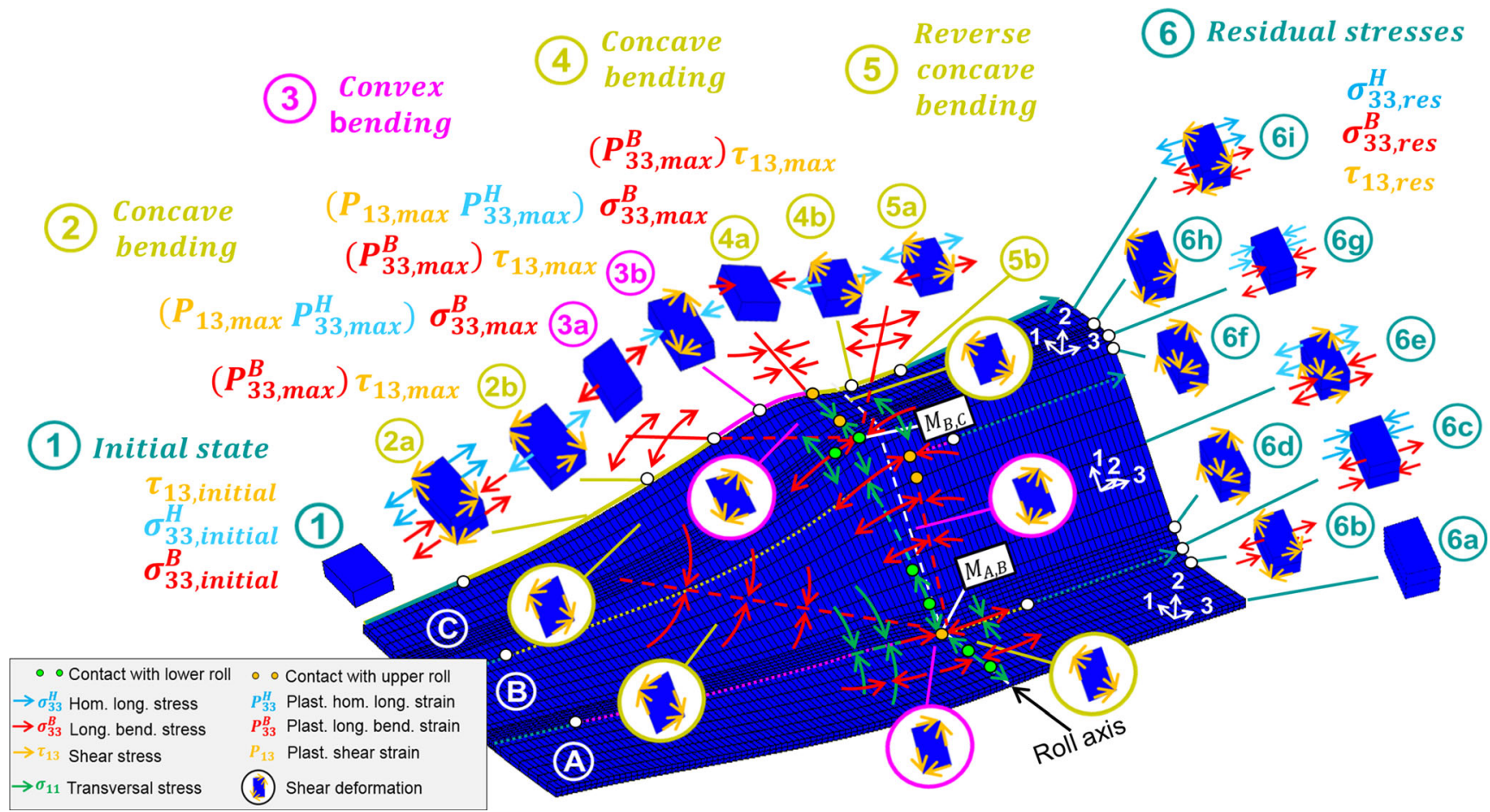

Fig. 33 Explanation model showing bending and shearing loads during roll forming of a Hat-profile as well as the creation of end flare and the remaining distribution of residual stresses along the cross section

"Reverse convex bending" (4) defined in Fig. 22. The creation of residual stresses in the upper part of flange B is described in Fig. 23. In the lower part, the creation of residual stresses and the forming steps correspond to the ones of the U-profile
(Fig. 11). The residual stresses across the cross section are described by characteristic points defined in Fig. 24. The deformation resulting from the release of the torsional and bending moments is shown in Fig. 25.
(3)
Convex
bending
(4) Reverse
convex
bending

(2) Concave

(1) Initial state
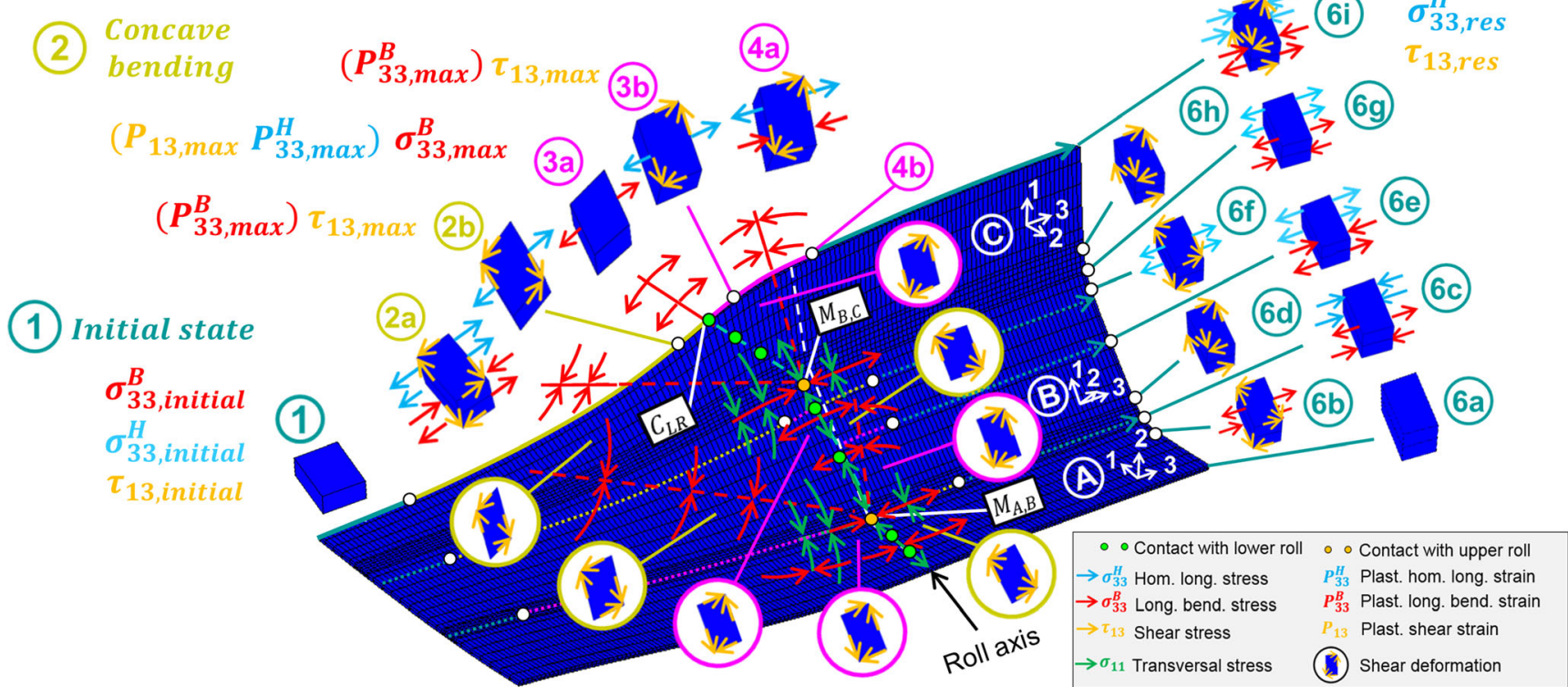

(6) Residual stresses $\sigma_{33 \text {,res }}^{B}$ $\sigma_{33 \text {,res }}^{H}$ $\tau_{13, \text { res }}$

Fig. 34 Explanation model showing bending and shearing loads during roll forming of a C-profile as well as the creation of end flare and the remaining distribution of residual stresses along the cross section 


\section{Conclusion}

In this study, the creation of plastic strain and residual stresses is investigated for U-, Hat- and C-profiles. Depending on the forming curve, characteristic forming steps are defined and the relations between transversal, longitudinal and shear stresses during the creation of plastic strains and residual stresses are investigated. This allows to bridge the gap between the forming curve and the distribution of residual stresses along the cross section. Based on the creation mechanism it can be evaluated how the residual stresses are affected by changes to the forming load. For profiles with multiple bends, it is shown how end flare is created at the inner and outer flanges as well the influence of the outer flange on the forming of the inner flange. As a result of this study explanatory models for the creation of end flare are developed, which incorporate the longitudinal bending, transversal bending and shear loads as well as the resulting distribution of residual stresses. The models allow for a knowledge-based approach instead of an experience-based approach when evaluating the influence of forming parameters on end flare during the design and setup process, thereby reducing the setup times and production costs.

Funding Open Access funding enabled and organized by Projekt DEAL. The authors did not receive support from any organization for the submitted work.

\section{Declarations}

Conflict of interest The authors declare that they have no conflict of interest.

Open Access This article is licensed under a Creative Commons Attribution 4.0 International License, which permits use, sharing, adaptation, distribution and reproduction in any medium or format, as long as you give appropriate credit to the original author(s) and the source, provide a link to the Creative Commons licence, and indicate if changes were made. The images or other third party material in this article are included in the article's Creative Commons licence, unless indicated otherwise in a credit line to the material. If material is not included in the article's Creative Commons licence and your intended use is not permitted by statutory regulation or exceeds the permitted use, you will need to obtain permission directly from the copyright holder. To view a copy of this licence, visit http://creativecommons.org/licenses/by/4.0/.

\section{References}

1. Volk W, Groche P, Brosius A, Ghiotti A, Kinsey B, Liewald M, Madej L, Min J, Yanagimoto J (2019) Models and modelling for process limits in metal forming. CIRP Ann Manuf Technol 68(2): 775-798. https://doi.org/10.1016/j.cirp.2019.05.007

2. Halmos G (2005) Roll forming handbook. CRC Press, Boca Raton

3. Lange K (1990) Handbook of metal forming 3. Springer, New York
4. Groche P, Müller C (2013) Merkblatt 180 - Walzprofilieren von Flacherzeugnissen aus Stahl. Stahl-Informations-Zentrum, ISSN 0175-2006, Düsseldorf

5. Sweeney K, Grunewald U (2003) The application of roll forming for automotive structural parts. J Mater Process Technol 132:9-15. https://doi.org/10.1016/S0924-0136(02)00193-0

6. Bogojawlenskij K, Neubauer A, Ris V (1979) Technologie der Fertigung von Leichtbauprofilen. VEB Deutscher Verlag der Grundstoffindustrie, Leipzig

7. Panton S, Zhu S, Duncan J (1992) Geometric constraints on the forming path in roll Forming Channel sections. Proc Inst Mech Eng B J Eng Manuf 206:113-118. https://doi.org/10.1243/PIME_ PROC $1992206063 \quad 02$

8. Yamakawa T (1963) Über die Verformung von Bandmaterial beim einstufigen V-förmigen Walzprofilieren. JSTP 4(35):783-795

9. Bhattacharyya D, Smith P, Yee C, Collins I (1984) The prediction of deformation length in cold roll-forming. J Mech Work Technol 9:181-191. https://doi.org/10.1016/0378-3804(84)90004-4

10. Liu C, Zhou W, Fu X, Chen G (2015) A new mathematical model for determining the longitudinal strain in cold roll forming process. Int J Adv Manuf Technol 79:1055-1061. https://doi.org/10.1007/ s00170-015-6845-4

11. Abeyrathna B, Rolfe B, Hodgson P, Weiss M (2017) Local deformation in roll forming. Int J Adv Manuf Technol 88:2405-2415. https://doi.org/10.1007/s00170-016-8962-0

12. Abeyrathna B, Rolfe B, Weiss M (2017) The effect of process and geometric parameters on longitudinal edge strain and product defects in cold roll forming. Int J Adv Manuf Technol 92(1-4):743754. https://doi.org/10.1007/s00170-017-0164-x

13. Zhu S, Panton S, Duncan J (1996) The effects of geometric variables in roll forming a channel section. Proc Inst Mech Eng B J Eng Manuf 210:127-134. https://doi.org/10.1243/PIME PROC 1996 210_098_02

14. Lindgren M (2007) An improved model for the longitudinal peak strain in the flange of a roll formed U-channel developed by FEanalyses. Steel Res Int 78(1):82-87. https://doi.org/10.1002/srin. 200705863

15. Paralikas J, Salonitis K, Chryssolouris G (2009) Investigation of the effects of main roll-forming process parameters on quality for a $\mathrm{V}$ section profile from AHSS. Int J Adv Manuf Technol 44(3-4):223237. https://doi.org/10.1007/s00170-008-1822-9

16. Bidabadi B, Naeini H, Tehrani M, Barghikar H (2016) Experimental and numerical study of bowing defects in cold rollformed, U-channel sections. J Constr Steel Res 118:243-253. https://doi.org/10.1016/j.jcsr.2015.11.007

17. Badr O M, Rolfe B, Hodgson P D Weiss M (2013) The Effect of Forming Strategy on the Longitudinal Bow in Roll Forming of Advanced High Strength Steel. In: Proceedings of the 9th International Conference and Workshop on Numerical Simulation of 3D Sheet Metal Forming Processes (NUMISHEET), January $6^{\text {th }}$ $-10^{\text {th }}, 2014$, AIP conference proceedings, No. 1567, 2013, pp. 876-879. https://doi.org/10.1063/1.4850110

18. Han Z, Liu C, Lu W, Ren L (2001) The effects of forming parameters in the roll-forming of a channel section with an outer edge. $\mathrm{J}$ Mater Process Technol 116:205-210. https://doi.org/10.1016/ S0924-0136(01)01041-X

19. Ona H, Jimma T (1983) Experiments into the cold roll-forming of straight asymmetrical channels. J Mech Work Technol 8:273-291. https://doi.org/10.1016/0378-3804(83)90012-8

20. Miyamoto Y, Hawa S (1991) Effect of tensile flow properties of titanium sheets on web-buckling behavior in cold roll-forming of wide profile. ISIJ Int 31(8):863-869. https://doi.org/10.2355/ isijinternational.31.863

21. Tölke K (1970) Unerwünschte Verformungen und Profilkrümmungen beim Walzprofilieren. Dissertation, Leibniz Universität Hannover 
22. Saffe S, Nagamachi T, Ona H (2015) Mechanism of end deformation after cutting of light Gauge Channel steel formed by roll forming. Mater Trans 56(2):187-192. https://doi.org/10.2320/ matertrans.P-M2014842

23. Ona H, Jimma T (1997) Distortion near cut-off edges of channel, Hat-Channel and C-channel sections. In: proceedings of the $32^{\text {nd }}$ international MATADOR conference, July $10^{\text {th }}-11^{\text {th }}, 1997$, Manchester, Macmillan publishers limited, 1997, pp. 475-480

24. Saffe S, Nagamachi T, Ona H (2014) Residual stress around cut end of hat steel channel by roll forming. Proced Eng 81:239-244. https://doi.org/10.1016/j.proeng.2014.09.157

25. Sagström E, Wadman B, Moshfegh R, Lundberg M, Melander A (2008) The Geometrical Robustness of Roll Formed Profiles in Ultra High Strength Steels. International Deep-Drawing Research Group (IDDRG), June $16^{\text {th }}-18^{\text {th }}, 2008$, Olofström, pp. 339-348

26. Saffe S, Nagamachi T, Ona H (2014) Effect of initial thickness to cut end deformation of hat Shape Channel steel by roll forming. Key Eng Mater 622-623:1132-1138. https://doi.org/10.4028/www. scientific.net/KEM.622-623.1132

27. Moneke M, Groche P (2017) Counter measures to effectively reduce end flare. In: proceedings of the 20th international ESAFORM conference on material forming, April $26^{\text {th }}-28^{\text {th }}, 2017$, Dublin, AIP conference proceedings, 1896(1), 2017, pp. 020006-1 020006-6. https://doi.org/10.1063/1.5007963

28. Moneke M, Groche P (2018) End flare of profiles with multiple bending zones. Proced Manuf 15:743-750. https://doi.org/10.1016/ j.promfg.2018.07.313

29. Nagamachi T, Nakako T, Nakamura D (2013) Mechanism of pipe end deformation after cutting of square steel pipe formed by roll forming. Mater Trans 54(10):1910-1915. https://doi.org/10.2320/ matertrans.P-M2013822

30. Moneke M, Groche P (2021) Control of residual stresses in roll forming through targeted adaptation of the roll gap J Mater Process Technol 294. https://doi.org/10.1016/j.jmatprotec.2021. 117129
31. Ona H, Jimma T, Utsunomiya N (1988) Elimination of distortion near the cut-off edges of cold roll-formed large thick channels. J Mech Work Technol 16(2):193-202. https://doi.org/10.1016/03783804(88)90160-X

32. N.N.: https://www.gom.com/de/messsysteme/atos.html, last access 19.03.2021 19:00

33. Müller C, Gu X, Baeumer L, Groche P (2014) Influence of friction on the loads in a roll forming simulation with compliant rolls. Key Eng Mater 611-612:436-443. https://doi.org/10.4028/www. scientific.net/KEM.611-612.436

34. Traub T, Chen X, Groche P (2017) Experimental and numerical investigations of the bending zone in roll forming. Int J Mech Sci 131-132:956-970. https://doi.org/10.1016/j.ijmecsci.2017.07.056

35. Marc Volume B (2012) Element Library, MSC.Software Corporation

36. Bui Q, Papeleux L, Ponthot J (2004) Numerical simulation of springback using enhanced assumed strain elements. J Mater Process Technol 153-154:314-318. https://doi.org/10.1016/j. jmatprotec.2004.04.342

37. Marc Volume A (2012) Theory and user information, MSC.Software Corporation

38. Li K, Carden W, Wagoner R (2002) Simulation of springback. Int J Mech Sci 44:103-122. https://doi.org/10.1016/S0020-7403(01) 00083-2

39. Abvabi A, Mendiguren J, Kupke A, Rolfe B, Weiss M (2017) Evolution of elastic modulus in roll forming. Int $\mathrm{J}$ Mater Form 10:463-471. https://doi.org/10.1007/s12289-016-1295-6

40. Liu X, Cao J, Chai X, Liu J, Zhao R, Kong N (2017) Investigation of forming parameters on springback for ultra high strength steel considering Young's modulus variation in cold roll forming. J Manuf Process 29:289-297. https://doi.org/10.1016/j.jmapro. 2017.08.001

Publisher's note Springer Nature remains neutral with regard to jurisdictional claims in published maps and institutional affiliations. 